\title{
EMFAZA LUI $N U$ LA FORMELE NEGATIVE ALE VERBULUI (II)
}

\author{
ADRIAN TURCULET
}

\section{INTRODUCERE}

În prima parte a acestui articol, publicată în FD, vol.XXXVII, am analizat auditiv şi acustic emfaza adverbului $n u$ în enunţuri asertive negative de tipul S(nu)VO, pe baza chestiunii twkn: Nevasta nu vede un căpitan din arhiva Atlasului multimedia prozodic român. Partea I (AMPROM I). În partea a II-a, vom urmări emfaza lui $n u$ în alte trei situații:

1) în enunțuri interogative negative, de tipul S(nu)VO?: chestiunea twkm. Nevasta nu vede un căpitan? ${ }^{1}$;

2) în enunțuri asertive negative care încep cu $n u$ : chestiunea a 12-a $N u$ l-am văzut pe Ion/Mihai;

3) în varianta enunțului de sub 2) în care $n u$ este urmat de un auxiliar începând cu vocala $a$ : chestiunea $14 N$-am văzut fetele.

Reluăm principalele aspecte ale demersului metodologic prezentat mai pe larg în prima parte. Cele trei enunțuri au fost rostite, de regulă, de câte trei ori $(1,2$, $3)$, de câte doi subiecți $(5=$ femeie şi $6=$ bărbat $)$ din 25 de oraşe.

Pentru analiza raportului de proeminență auditivă a celor două vocale din silabele $n u$ (enunțurile 1,2) şi $n(u) a m$ (enunțul 3), pe de o parte, respectiv, ve (enunțul 1) şi zut (enunţurile 2,3), pe de altă parte, am ascultat toate exemplele înregistrate: 150 (iteme, repetiții) pentru primul enunț (twkm), 190 pentru al doilea

\footnotetext{
${ }^{1}$ Am renunțat la folosirea unor determinanți ai subiectului cu structuri accentuale diferite (nevasta tinerea, frumoasă, harnică), ca în prima parte, în urma observației că asemenea determinări nu influențează raportul accentual dintre $n u$ și silaba accentuată a verbului. Situațiile 2 şi 3 au fost ilustrate în analiza acustică tot cu câte un singur enunț, repetat, de regulă, de trei ori.
}

FD, XXXVIII, Bucureşti, 2019, p. 101-126 
enunț (12a) şi 162 pentru al treilea enunț (14). Raporturile accentuale au fost descrise cu ajutorul datelor acustice prezentate în Tabelul 2 şi ilustrate cu ajutorul unor enunțuri analizate în Praat. Am urmărit repartiţia teritorială a emfazei adverbului $n u$ şi a alomorfului său $n(u)$-am.

Tabelul 2 cuprinde trăsăturile acustice: durata $(\mathrm{D}$, măsurată în sutimi de secundă), intensitatea fizică (I, măsurată în decibeli) şi frecvența fundamentală (F0, măsurată în herşi) ale vocalelor analizate: $(n) u$ şi $(n-) a(m)$, respectiv, (v)e şi $(z) u(t)$ din cele trei serii de enunţuri înregistrate în şase localități selectate şi în partea întâi a articolului: Bucureşti $=\mathbf{B}$, Baia Mare $=\mathbf{B M}$, Craiova $=\mathbf{C r}$, Constanţa $=\mathbf{C s}^{2}$, Iaşi $=\mathbf{I s s}$, Timişoara $=\mathbf{T}$. Am marcat cu bold diferențele mai clar perceptibile de durată: valoarea egală cu/sau mai mare de o treime din valoarea mai mică, intensitate: de $1 \mathrm{~dB}$ sau mai mare şi de frecvență: egală cu/sau mai mare de $15 \mathrm{~Hz}$.

\section{ENUNȚURI INTEROGATIVE TOTALE NEGATIVE - twkm:}

Nevasta nu vede un căpitan?

Conturul melodic al interogativelor totale negative corespunde, în general, cu cel al interogativelor totale afirmative. În timp ce, în enunţurile asertive negative, emfaza adverbului $n u$ realizează focalizarea contrastivă a verbului ("nu véde vs. véde), în interogativele totale negative, verbul poartă accentul principal, „conținutul" vizat de întrebare fiind, în primul rând, semantica verbului. Emfaza adverbului apare numai sporadic ${ }^{3}$.

Proeminența auditivă $n u$ vé caracterizează majoritatea enunțurilor; în 117 din 150 de cazuri $=78 \%, n u$ se prezintă ca simplu morfem de negație a formei verbale $n u$ vede. Dominanța accentuală a verbului este dată, în primul rând, de intensitatea mai mare a silabei/vocalei (v)é prezentă în aproape toate exemplele analizate în tabelul 2 .

La vorbitorii care au un „stil linear” de rostire a interogativelor (aproape plat, până la ascensiunea finală), proeminența acustică/auditivă a lui (v)é se exprimă printr-o uşoară creştere a intesității, v. fig. 1 şi tabelul 2: B5 twkm1.

2 În partea I sigla Constanței a fost notată cu Cț, care este, de fapt, sigla Cernăuțiului (cf. partea întâi, nota 10). Altă scăpare în partea I, la p. 141: a se citi fig. 3 în loc de fig.1.

${ }^{3}$ Această deosebire între enunțurile asertive negative și cele interogative corespunzătoare în privința emfazei lui $n u$ a fost semnalată în Turculeț et alii 2008, p. 44 și urm. 


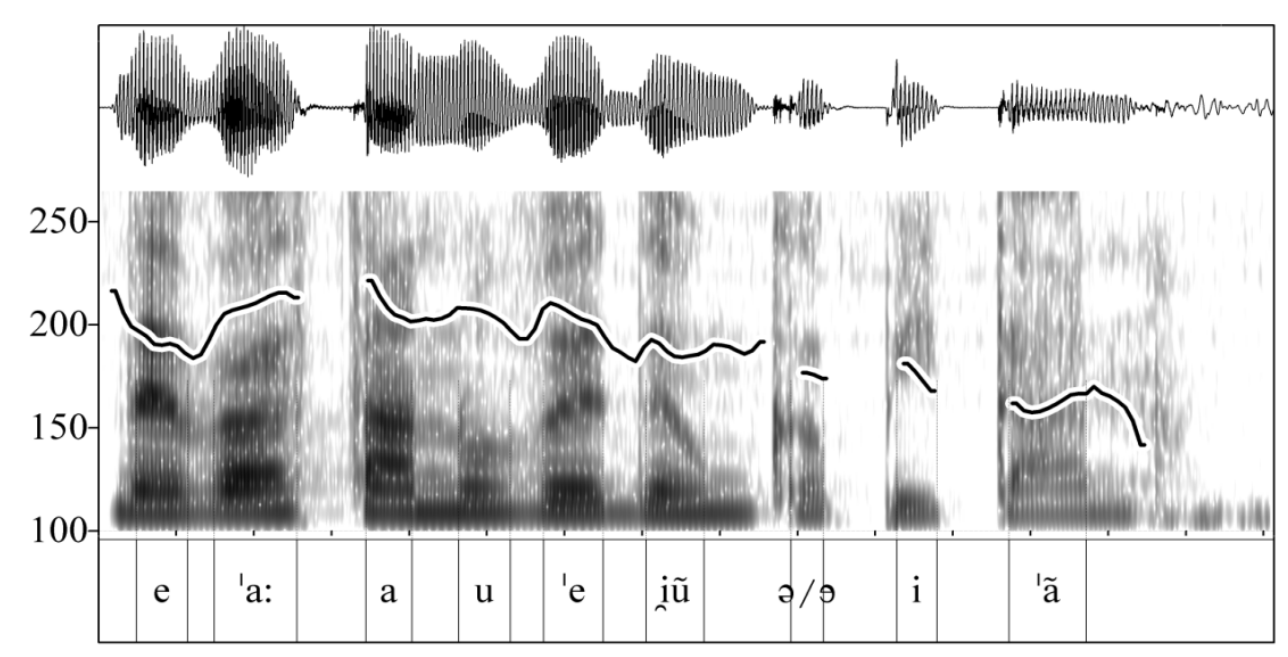

Fig. 1. Oscilograma şi spectrograma enunțului B5twkm1: Nevasta nu vede-un căpitan? Proeminența auditivă $n u$ vé.

În rostirea emfatică a verbului, mai ales la vorbitorii ardeleni (v. BM5twkm2, BM6twkm1-3, T5twkm1-3, T6twkm1-3), am notat preponderența accentuală a lui ve în raport cu $n u$ prin accent dublu: $n u$ "ve, fiind accentul principal (nuclear) al enunţului. Creşterii intensității pe "ve i se adaugă înălţimea şi/sau durata mai mare; v. fig. 2 şi datele pentru BM5twkm1 din tabel. Atunci când tonul final coboară pe silaba finală accentuată ${ }^{4}, n u$ se află la nivelul cel mai de jos al curbei intonative, iar emfaza lui "ve se extinde asupra silabelor următoare până la silaba accentuată finală, pe care F0 coboară.

Adverbul $n u$ dominat accentual de ve poate avea intensitatea, durata sau o valoare F0 maxime în cadrul sintagmei verbale, primind un accent secundar sau chiar unul normal; am notat proeminența nù "ve sau nù vé în cinci exemple (v., de ex., datele din tabel pentru Cr6twkm1, Cs5twkm2, Iş5twkm1,2) şi nú "ve în şapte exemple, iar în opt cazuri, atât $n u$, cât şi verbul par a avea valori egale: $n u ́$ vé, ca în Cs5twkm3, unde primul accent este melodic, iar al doilea de intensitate.

Un număr redus de exemple - $14(9.33 \%)$ atestă tendinţa de extindere a emfazei adverbului $n u$ şi la enunțurile interogative negative, v. fig. 3: Cr5twkm1 cu valori superioare de I şi F0 ale lui (n)u față de (v)e (v. şi tabelul 2).

${ }^{4}$ V. Turculeț et alii, p. p. 42. Aria acestui contur intonativ interogativ final, numit de noi descendent inalt, cuprinde graiurile ardelenești, dar şi multe graiuri din Bucovina de Nord și Basarabia, v. Turculeț 2017. 


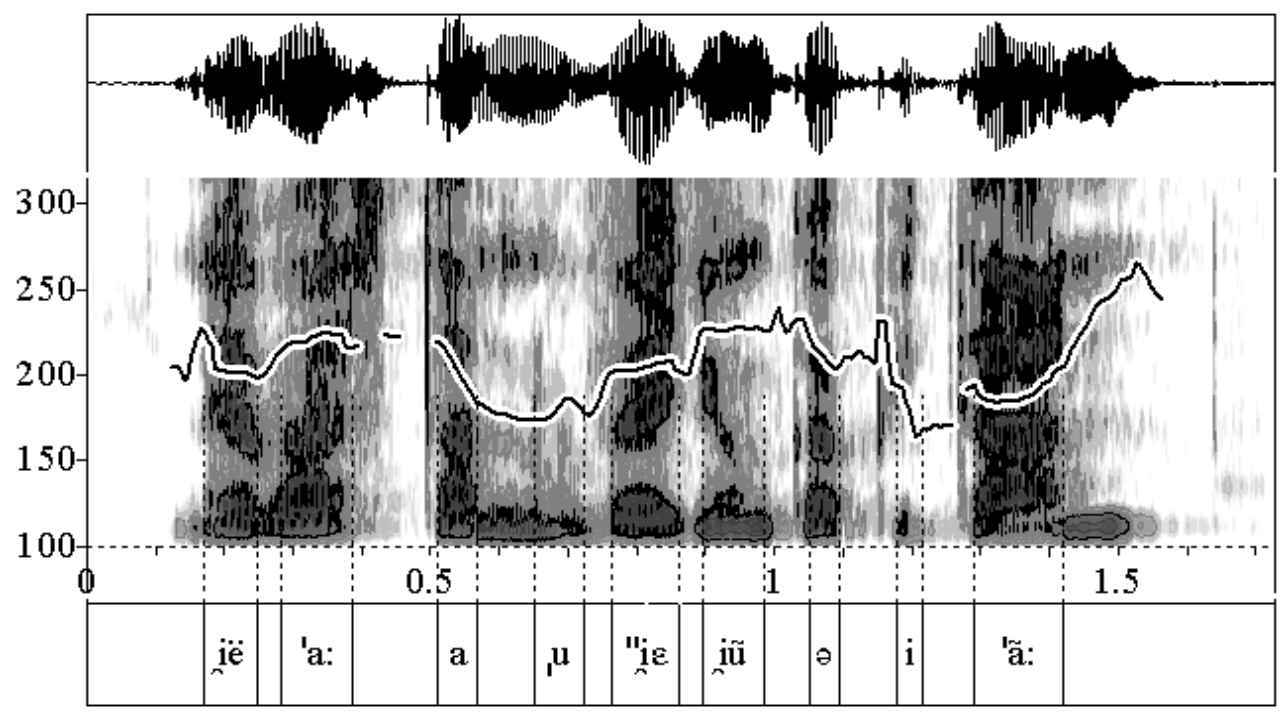

Fig. 2. Oscilograma şi spectrograma enunțului B5twkm1 Nevasta nu vede-un căpitan?

Accentul silabei ve are vârful întârziat, atinge I cea mai mare în enunț şi F0 cea mai înaltă (cu excepția emfazei interogative) pe silaba următoare $\left(\mathrm{L}+>\mathrm{H}^{*}\right)$; emfaza silabei ve este mai slabă decât cea a conturului final ascendent; pe $n u$ începe lent creşterea F0; proeminență auditivă nù "ve.

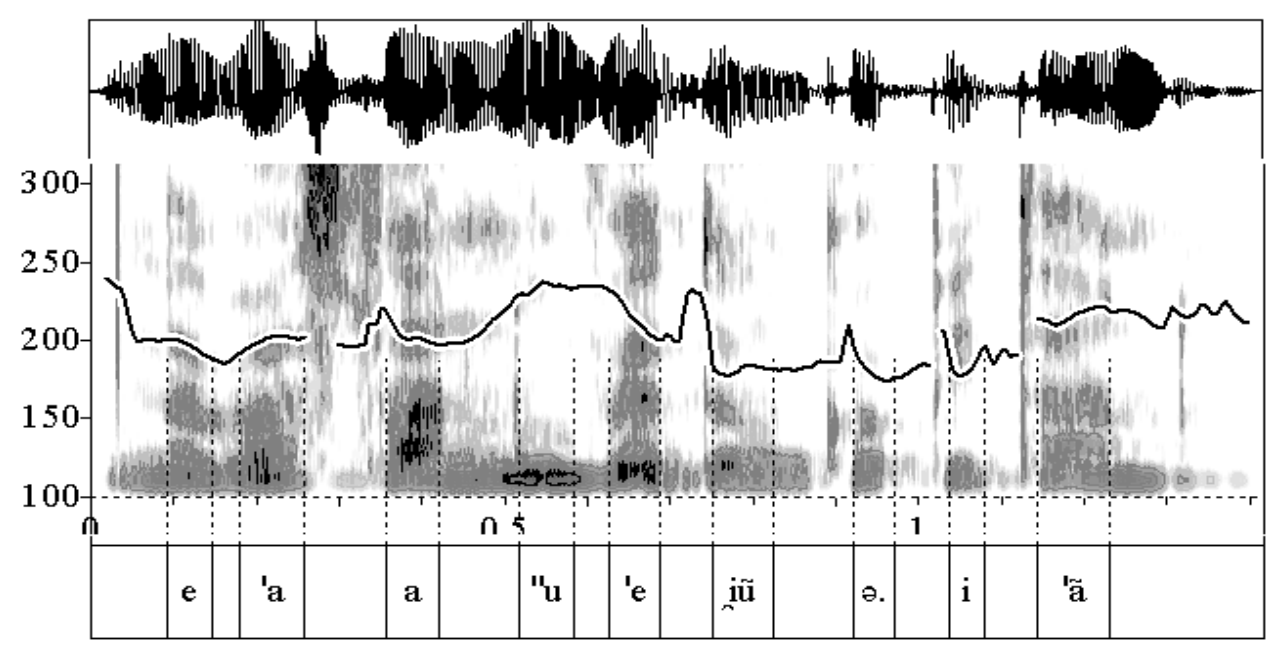

Fig. 3. Oscilograma şi spectrograma enunțului B5twkm1: Nevasta nu vede-un căpitan? $N u$ deține I şi F0 maxime în enunț; proeminența auditivă "nu vé.

În toate cele 14 exemple, $n u$ are cea mai mare valoare F0 din cadrul enunțului, care poate fi depăşită însă de ascensiunea F0 în emfaza interogativă 
finală. $\mathrm{Cu}$ cât emfaza este mai puternică, cu atât curba $\mathrm{F} 0$ trasată de $n u$ are un vârf mai înalt, accentul căpătând o formă mai apropiată de circumflex. Extinderea emfazei adverbului $n u$ este împiedicată de semantica interogativelor totale care pune sub semnul întrebării realizarea acțiunii verbului, probabil, şi de dificultatea producerii a două secvențe emfatice succesive în acelaşi enunț ${ }^{5}$.

Ca realizare spontană sporadică, emfaza adverbului $n u$ în interogativele totale nu formează arii specifice. Cum era de aşteptat, ea apare la vorbitori care obişnuiesc să rostească $n u$ emfatic în asertivele negative. Cele 14 exemple înregistrate sunt: Cr5twkm1, Cs6twkm1-3 (v. tabelul 2), Fş7twkm2,3, Bztwkm1, Tg5twkm1, Tg6twkm2,3, TM6twkm3, BN5twkm1-3, Cț5twkm2. Cei trei subiecți care au emfatizat pe $n u$ în două sau trei repetiții au, prin profesia lor (Cs6 - actor, Fş7 - profesor de liceu şi redactor la postul de radio local, BN5 - funcționară la prefectură pe probleme de comunicare), preocupări speciale pentru expresivitatea vorbirii. Ei au rostit emfatic şi verbul, ba chiar toate unitățile accentogene ale enunţului.

\section{NU ÎN POZIȚIE INIȚIALĂ DE ENUNȚ: 12a - Nu l-am văzut pe Ion/Mihai}

În enunțul cercetat, adverbul $n u$ se află în poziţie inițială şi la distanţă de trei silabe față de silaba accentuată a verbului. Poziția inițială este favorabilă actualizării accentului lui $n u$, prin faptul că, după cum observa S. Puşcariu (1940/1976: 71; 1959/1990: 189), o caracteristică a sistemului fonetic românesc este masarea energiei articulatorii la începutul enunțului, care se rosteşte cu o intensitate mai mare, pe un ton mai înalt şi, adesea, cu o durată mai mare a sunetelor. În fig. 4 Cr5_12_3, silaba $n u$ se află la nivelul cel mai înalt (uşor ascendent) al intensităţii şi al curbei F0, fiind percepută cu un accent mai proeminent decât cel al verbului, chiar dacă nu are un accent emfatic. Un alt factor care favorizează accentuarea lui $n u$ este distanţa față de silaba accentuată a verbului. Astfel, adverbul primeşte, în toate cazurile, un accent de pozție + ritmic care predomină asupra accentului verbal, chiar atunci când nu devine particulă emfatică.

Un caz asemănător de accentuare ritmică prezintă articolul aflat în poziţie inițială în enunțul Un căpitan vede nevasta: un primeşte frecvent un accent ritmic secundar în cadrul unităţii accentuale un căpitan sau chiar îşi actualizează accentul lexical de la valorile morfologice de adjectiv pronominal sau de numeral.

\footnotetext{
${ }^{5}$ Interogativa totală este marcată printr-o emfază (ridicare a tonului), de regulă, în conturul final al enunțului. În rostirea emfatică pot primi însă accent emfatic mai multe sau chiar toate unitățile accentogene, cum se întâmplă, de ex., în rostirea afectivă, sacadată, din enunțul BN5twkm2.
} 


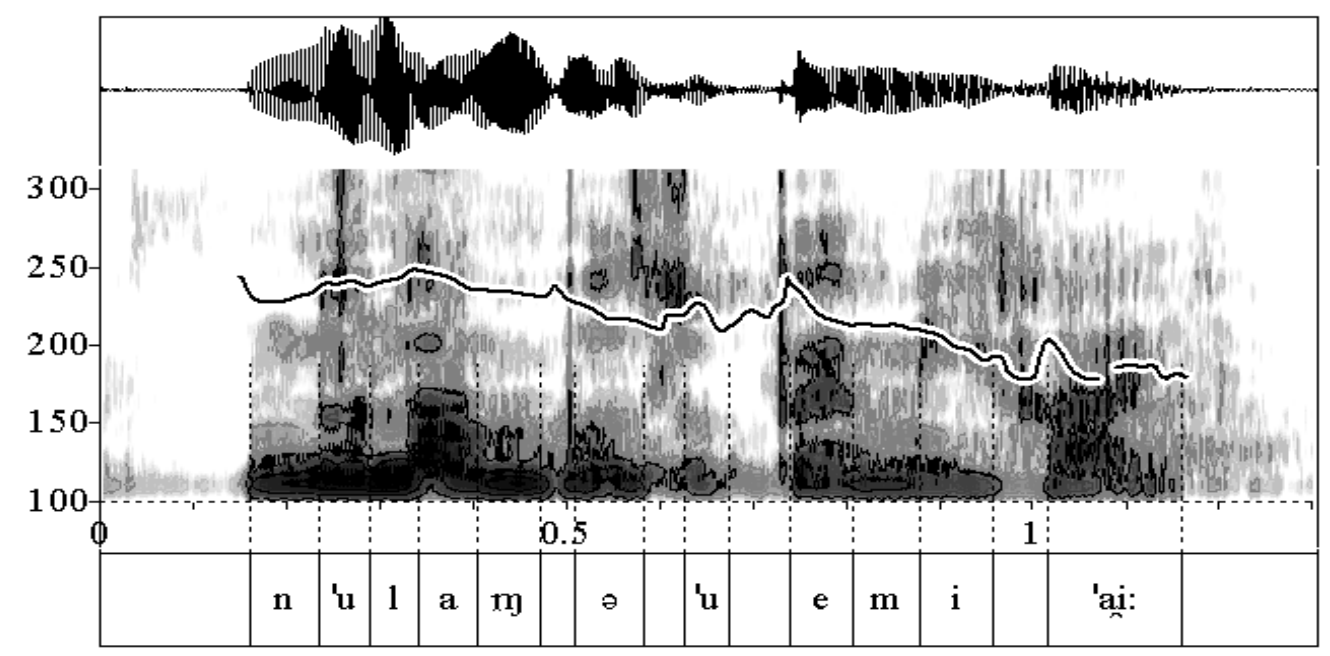

Fig. 4. Oscilograma şi spectrograma enunțului Cr5 12 _ 3 Nu l-am văzut pe Mihai. Nu cu accent de poziție + ritmic, mai proeminent auditiv față de silaba accentuată a verbului: 'nu zút.

Predominarea accentuală a lui $n u$, chiar în cazul în care proeminența auditivă pare relativ egală: 'nu - zút (vezi, de ex., B6_12_1, 2, Cr5_12_2, 3, 5, 6 etc.) ${ }^{6}$ facilitează apariția emfazei adverbului: "nu-zút, care se percepe, cu unele oscilații ale impresiei auditive între $n u ́$ şi "nu, în marea majoritate (87\%) a celor 190 de iteme cercetate. Ca accent de poziție şi ritmic, întărit prin emfază, accentul adverbului $n u$ domină accentul verbului prin intensitate şi înălţime, uneori şi prin durată (vezi tabelul 2). În unele cazuri, vocala $u$ se deschide: [ụ o o].

După mişcarea curbei melodice pe silaba $n u$ se pot deosebi cinci tipuri:

a) F0 formează un vârf (accent circumflex) situat pe vocala $u$; vezi fig. 6 BM5 123 ;

b) F0 formează o „buclă” care se extinde şi peste silaba următoare; accentul emfatic al silabei $n u$ are vârful întârziat: $\mathrm{L}+>\mathrm{H}^{*}$; vezi fig. 7 Iş5_12_2;

c) F0 începe cu $n$ în registrul cel mai înalt al vorbitorului şi coboară pe vocala $u$; accentul tonal al silabei $n u$ are vârful timpuriu: $\mathrm{H}+<! \mathrm{H}$, vezi fig. 8 Cs5_12_1;

d) F0 are un mers linear, dar cu nivelul cel mai înalt pe silaba $n u$; cf. fig. 3 ; percepția auditivă poate oscila între accentul emfatic i cel neemfatic, dar întărit prin poziție.

e) F0 are un mers mai plat decât la d; proeminența nú - zút, cu nú mai proeminent, dar neemfatic.

\footnotetext{
${ }^{6}$ Notarea 'nu zút din tabelul 2 înseamnă că $n u$, fără să aibă accent emfatic, are o proeminență auditivă mai mare față de vocala verbului, dar mai mică decât cea a emfaticului "nu zút.
} 
Tipurile de contururi melodice inițiale $\underline{a}, \underline{b} \underline{\text { şi }} \underline{\mathrm{c}}$, urmate de o coborâre decisă a liniei F0 până la finalul enunțului se regăsesc la interogativele parțiale (Turculeț, Bleorțu, Bibiri 2015) şi la propozițiile imperative care încep cu verbul, de tipul: Lasă-mă (în pace)!

Tipurile a şi c oferă gradul maxim de perceptibilitate auditivă a emfazei adverbului. La tipul $\underline{b}$, emfaza se extinde şi la silaba următoare, pe care creşte şi intensitatea. În cazuri rare, impresia auditivă este aceea a unui accent emfatic compus dintr-un accent muzical pe $n u$ şi un accent de intensitate pe silaba următoare.

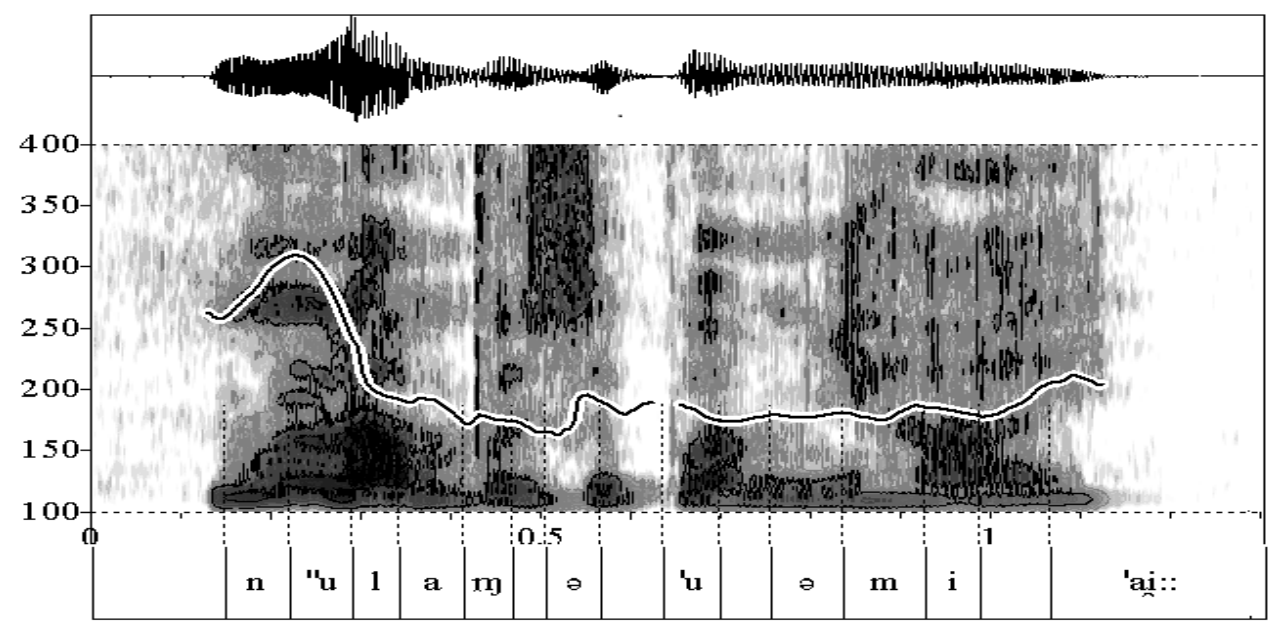

Fig. 5. Oscilograma şi spectrograma enunțului BM5_12_3 Nu l-am văzut pe Mihai. $N u$ cu accent emfatic circumflex; proeminența auditivă "nu zút.

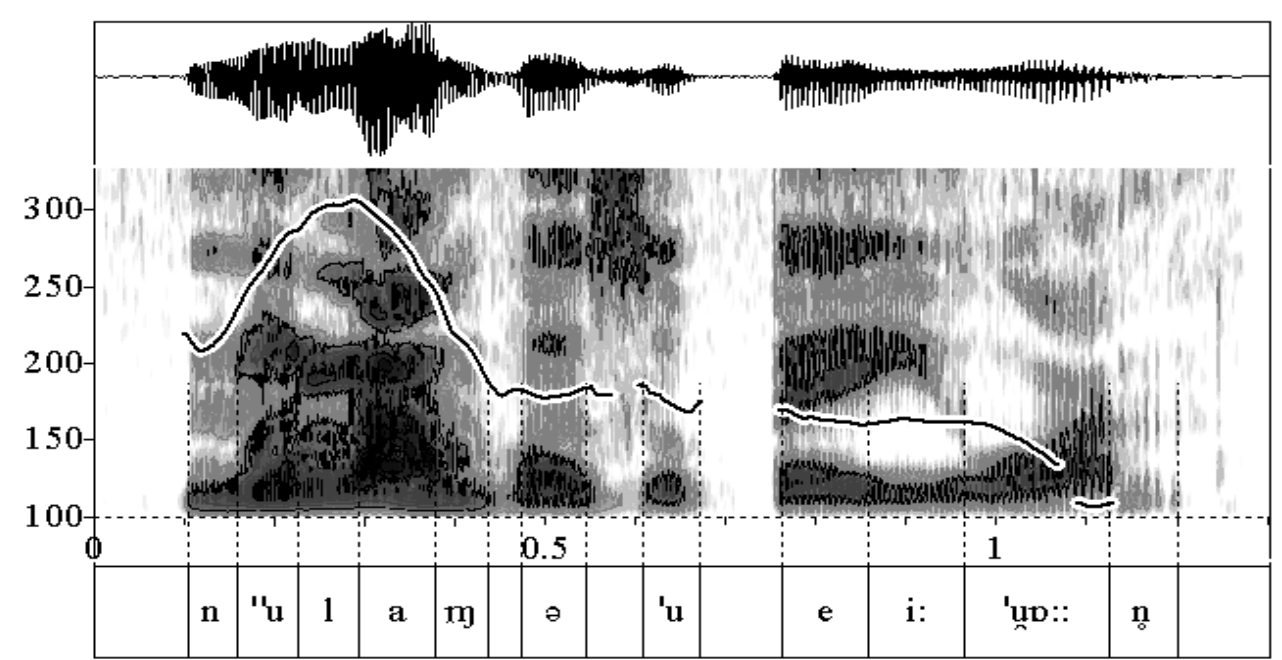

Fig. 6. Oscilograma şi spectrograma enunţului Iş5_12_2 Nu l-am văzut pe Ioan. $N u$ cu accent emfatic care se extinde pe silaba următoare; proeminența auditivă "nu zút. 


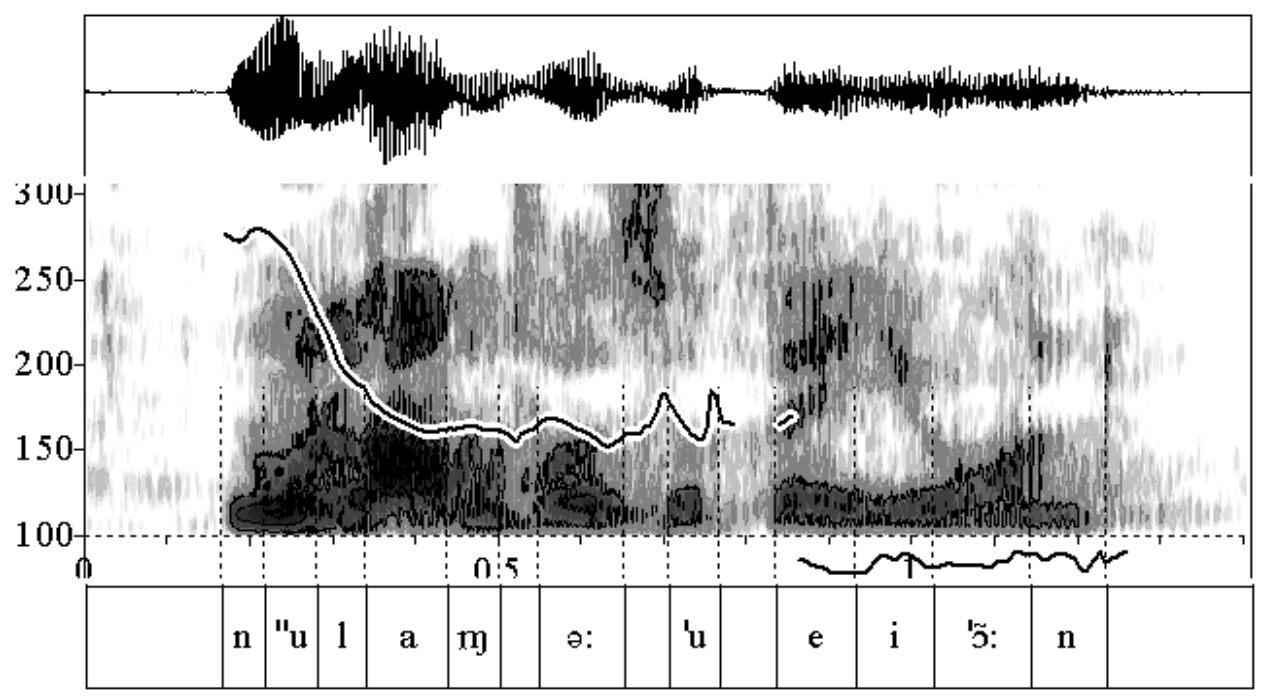

Fig. 7. Oscilograma şi spectrograma enunțului Cs5_12_1 Nu l-am văzut pe Ion. Accentul emfatic pe $n u$ cu vârf timpuriu; proeminența auditivă "nu zút.

În ceea ce priveşte răspândirea teritorială a rostirii emfatice a adverbului $n u$ în poziție inițială, aceasta este generală: în cea mai mare parte a localităților anchetate, şi anume, 17 din 25, emfaza lui $n u$ a fost înregistrată în toate exemplele, iar în alte patru localități în proporție majoritară; rate mai reduse ale emfatizării au fost notate numai în patru localităţi: Craiova -6 ex. din 13; Bucureşti şi Cahul -3 ex. din 5 şi Timişoara -4 ex. din 6 . Nu există niciun informator şi niciun punct anchetat la care să nu predomine proeminenşa auditivă a adverbului $n u$ în poziție inițială în raport cu cea a silabei accentuate a verbului (v. tabelul 2), fie că adverbul poartă accent emfatic, fie că are un accent întărit prin poziție.

\section{NU ÎN POZIȚIE INIȚIALĂ URMAT DE VOCALĂ DESCHISĂ -} 14: $N(u)$-am văzut fetele

În vorbirea literară colocvială, alomorful $n$-, rezultat prin eliziunea lui $u$ înaintea vocalei $a$ a devenit realizarea obişnuită a adverbului. Numai în şapte exemple s-a înregistrat păstrarea lui $u$ vocalic: $N u$ am văzut fetele şi, în cinci exemple, transformarea acestuia în semivocală: Nu-am văzut fetele. În primul caz avem, de fapt, un „fals” hiat, între cele două vocale nefiind nicio limită perceptibilă, mai mult chiar, ele sunt reunite în cadrul accentului emfatic al lui "nu, care se extinde şi asupra vocalei următoare, v. fig. 8 Bt_14_5. Cele două vocale se acomodează reciproc, prin deschiderea lui $u$ şi labializarea lui $a$. Etapa următoare, înainte de ,înghițirea" lui $u$, este transformarea falsului hiat în diftong, v. datele din tabelul 2 pentru Cs6_14_1. 


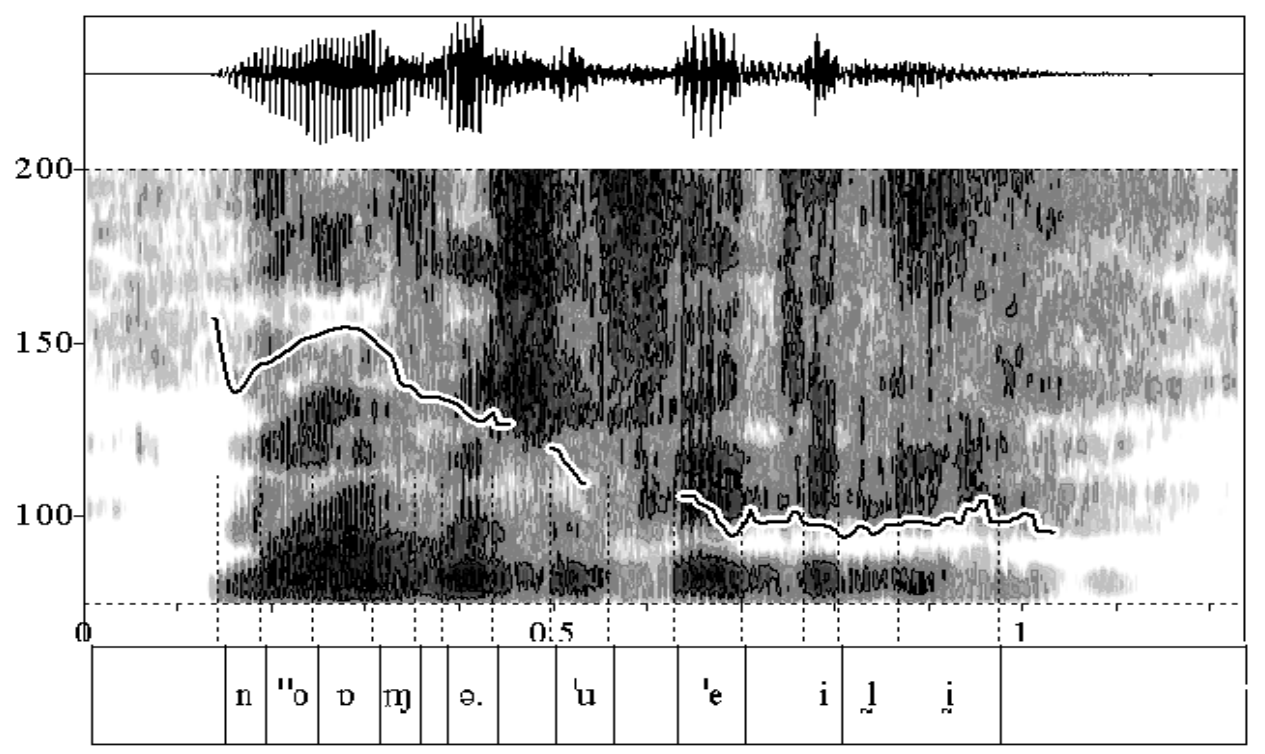

Fig. 8. Oscilograma şi spectrograma enunțului Bt6_14 5 Nu am văzut fetele.

Accentul emfatic pe $n u$ se extinde pe silaba următoare; proeminența auditivă "nu zút.

Vocala $a$ preia toate caracteristicile prozodice ale fostei vocale $u$ din adverbul $n u$ sau, mai exact, silaba cu accent emfatic "nu devine "na(m). Chiar dacă auzul nu percepe un accent emfatic propriu-zis, cum se întâmplă în 16 exemple notate la subiecți din Alba Iulia (inf. 6), Bistrița-Năsăud (5), Bucureşti (6 în toate cele 3 repetiții), Buzău (6), Cahul $(5,6)$, Cernăuți (6), Cluj-Napoca $(6,7,8)$, Craiova (5), silaba $n$-am are accentul predominant, prin poziție, în sintagma verbală (v. datele B6_14_1 în tabel). Notarea ' $n$-am - zút din tabelul 2 înseamnă că $n u$ nu are accent emfatic, dar are o proeminență auditivă față de vocala verbului mai mică decât cea notată "nu zút.

Tipurile de contururi melodice emfatice pe silaba $n$-am sunt aceleaşi ca la adverbul $n u$ în poziție inițială (v. sub 2), cu unele deosebiri: a) cu vârf circumflex pe $a$ (de ex. BM5_14_1); b) cu „buclă” formată de ascensiunea F0 pe toată silaba $n$-am (de ex. Iş5_14_1); c) F0 începe cu $n$ - în registrul cel mai înalt al vorbitorului şi coboară pe $a$, în timp ce intensitatea creşte; d) enunţul începe cu un nivel mai ridicat al F0 şi al intensității pe silaba $n$-am (B5_14_1). Tipul b nu prezintă (cu trei excepții, de rostire ezitantă, la inf. Fş6_14_1,4 şi Cțt6_14_2) extinderea emfazei pe silaba următoare: vă (zut), păstrându-se limita dintre emfază şi accentul normal al verbului. Tipul c (în care emfaza începe cu $n$ ) este mai frecvent, fiind prezent în toate repetiţiile unor informatoare ardelene (Alba Iulia, Braşov), dar şi din Buzău sau Cernăuți. Emfaza se percepe cel mai clar la tipurile a şi $\underline{c}$. La tipul $\underline{\mathrm{d}}$ impresia auditivă poate oscila între accent emfatic şi accent întărit (de poziție). La tipul e 
nivelul intensității şi al lui F0 pe $n$-am este numai puțin ridicat (aproape plat) şi coboară lent pe silabele verbului.

Emfaza silabei $n$-am este aproape generală, cu frecvență de $91 \%$ în corpusul noastru; în puține cazuri, (curba melodică de tip e), accentul pe $n$-am nu este perceput ca emfatic, ci ca un accent de intensitate cu proeminență mai mare decât cel al verbului, întărit prin poziția inițială în enunț.

\section{ÎNCHEIERE}

Am cercetat proeminența auditivă a adverbului $n u$ (cu alomorfele $n u$-, $n$-) în raport cu silaba accentuată a verbului (ve-, -zut), utilizând principalele trăsături acustice (durata, intensitatea şi frecvența fundamentală) ale vocalelor din silabele respective. Din arhiva Atlasului multimedia prozodic român. Partea I am extras un corpus cu adverbul $n u$ la forme negative ale verbului a vedea ( $n u$ vede, $n$-am văzut), aflat în mai multe situații:

- în interiorul unui enunț asertiv negativ: Nevasta/tânără/frumoasă/harnică $\boldsymbol{n} \boldsymbol{u}$ vede un căpitan (600 iteme);

- în interiorul unui enunț interogativ negativ: Nevasta nu vede un căpitan? (150 iteme);

- în poziție inițială de enunț asertiv: Nu l-am văzut pe Ion/Mihai (190 iteme);

- în aceeaşi poziție iniţială urmat de vocala $a$ : $N(\boldsymbol{u})$-am văzut fetele (162 iteme).

În tabelele 1 şi 2 care prezintă datele acustice au fost incluse, din motive de spațiu, numai datele din şase puncte anchetate din zone diferite.

Am deosebit patru ipostaze ale negației $n u$ (cu alomorfele $n u$-, $n$-):

$n u_{1}$ - particulă negativă, morfem al formei negative a verbului; neaccentuat sau cu accent slab (secundar);

$n \dot{u}_{2}-$ (semi)adverb, mijloc lexical-sintactic al negației verbului; cu accent lexical propriu;

$' n u_{3}$ - (semi)adverb, mijloc lexical-sintactic al negației verbului; cu accent lexical propriu întărit prin poziția iniţială de cuvânt;

"nu - (semi)adverb şi particulă emfatică, morfem al focalizării contrastive a formei negative a verbului; cu accent emfatic (emfază).

În poziție iniţială de enunţ, adverbul-particulă emfatică " $n u$ este cvasigeneralizat: în exemplele noastre, are frecvența $87 \%$ şi peste $90 \%$ în cazul alomorfului " $n(u)$-. Este poziția cea mai favorabilă emfatizării, deoarece adverbul $n u$ are accentul său întărit prin poziția inițială. Este plauzibilă ipoteza că în această poziţie s-a produs mai întâi emfatizarea lui $n u$ şi generalizarea (gramaticalizarea) acesteia, care s-a extins ulterior şi în interiorul enunțurilor asertive, unde atinge, în corpusul nostru, o frecvență medie de peste $50 \%$ (v. partea I). În interiorul enunţurilor interogative totale există tendința sporadică de extindere a emfazei lui 
$n u$, frânată de semantica propoziției interogative şi de prezența (în conştiinţa vorbitorului a) emfazei interogative care marchează caracterul interogativ al enunțului.

ANEXĂ: TABEL 2

\begin{tabular}{|c|c|c|c|c|c|c|c|c|}
\hline $\begin{array}{l}\text { Infor- } \\
\text { mator }\end{array}$ & Enunț & D & I & F0 (F) & , F2, & F3) & $\begin{array}{l}\text { Proeminență } \\
\text { auditivă }\end{array}$ & $\begin{array}{l}\text { Indici } \\
\text { acustici }\end{array}$ \\
\hline \multirow[t]{9}{*}{ B5 } & twkm1 nu & $\begin{array}{l}60 \\
70\end{array}$ & $\begin{array}{l}69 \\
75\end{array}$ & $\begin{array}{l}192 \\
191\end{array}$ & $\begin{array}{l}187 \\
190\end{array}$ & $\begin{array}{l}184 \\
184\end{array}$ & nu vé & ve: I \\
\hline & $\begin{array}{ll}\text { twkm2 nu } \\
\\
\text { ve }\end{array}$ & $\begin{array}{l}62 \\
74\end{array}$ & $\begin{array}{l}75 \\
77\end{array}$ & $\begin{array}{l}207 \\
202\end{array}$ & $\begin{array}{l}201 \\
198\end{array}$ & $\begin{array}{l}194 \\
193\end{array}$ & nu vé & ve: I \\
\hline & $\begin{array}{ll}\text { twkm3 nu } & \text { ve } \\
\end{array}$ & $\begin{array}{l}56 \\
68 \\
\end{array}$ & $\begin{array}{l}76 \\
78 \\
\end{array}$ & $\begin{array}{l}197 \\
199 \\
\end{array}$ & $\begin{array}{l}195 \\
196 \\
\end{array}$ & $\begin{array}{l}189 \\
189\end{array}$ & nu vé & ve: I \\
\hline & $\begin{array}{c}12 \_1 \mathrm{nu} \\
\text { (vă)zut }\end{array}$ & $\begin{array}{l}48 \\
50 \\
\end{array}$ & $\begin{array}{l}80 \\
71 \\
\end{array}$ & $\begin{array}{l}218 \\
170 \\
\end{array}$ & $\begin{array}{l}220 \\
169 \\
\end{array}$ & $\begin{array}{l}217 \\
156 \\
\end{array}$ & "nu zút & nu: I, F0 \\
\hline & $\begin{array}{c}12 \_\mathrm{nu} \\
\text { (vă)zut }\end{array}$ & $\begin{array}{l}49 \\
40 \\
\end{array}$ & $\begin{array}{l}80 \\
71 \\
\end{array}$ & $\begin{array}{l}217 \\
171 \\
\end{array}$ & $\begin{array}{l}219 \\
169 \\
\end{array}$ & $\begin{array}{l}217 \\
160 \\
\end{array}$ & "nu zút & nu: I, F0 \\
\hline & $\begin{array}{c}12 \_3 \mathrm{nu} \\
\text { (vă)zut }\end{array}$ & $\begin{array}{l}50 \\
41 \\
\end{array}$ & $\begin{array}{l}81 \\
73 \\
\end{array}$ & $\begin{array}{l}230 \\
171 \\
\end{array}$ & $\begin{array}{l}237 \\
170 \\
\end{array}$ & $\begin{array}{c}235 \\
168 \\
\end{array}$ & "nu zút & nu: I, F0 \\
\hline & $\begin{array}{l}\text { 14_1 n-am } \\
\text { (vă)zut }\end{array}$ & $\begin{array}{l}83 \\
68 \\
\end{array}$ & $\begin{array}{l}79 \\
75\end{array}$ & $\begin{array}{l}200 \\
157\end{array}$ & $\begin{array}{l}200 \\
152\end{array}$ & $\begin{array}{l}194 \\
141\end{array}$ & "n-am zút & n-am: I, F0 \\
\hline & $\begin{array}{l}14 \_2 \text { n-am } \\
\text { (vă)zut }\end{array}$ & $\begin{array}{l}74 \\
75 \\
\end{array}$ & $\begin{array}{l}80 \\
76 \\
\end{array}$ & $\begin{array}{l}200 \\
158 \\
\end{array}$ & $\begin{array}{l}200 \\
152 \\
\end{array}$ & $\begin{array}{l}194 \\
145\end{array}$ & "n-am zút & n-am: I, F0 \\
\hline & $\begin{array}{l}14 \_3 \text { n-am } \\
\text { (vă)zut }\end{array}$ & $\begin{array}{l}72 \\
61 \\
\end{array}$ & $\begin{array}{l}81 \\
66 \\
\end{array}$ & $\begin{array}{l}233 \\
185 \\
\end{array}$ & $\begin{array}{l}239 \\
179 \\
\end{array}$ & $\begin{array}{l}241 \\
170 \\
\end{array}$ & "n-am zút & n-am: I, F0 \\
\hline \multirow[t]{8}{*}{ B6 } & $\begin{array}{ll}\text { twkm1 nu } & \text { ve }\end{array}$ & $\begin{array}{l}65 \\
90\end{array}$ & $\begin{array}{l}75 \\
77\end{array}$ & $\begin{array}{l}96 \\
91\end{array}$ & $\begin{array}{l}92 \\
88\end{array}$ & $\begin{array}{l}88 \\
84\end{array}$ & nu vé & ve: D, I \\
\hline & $\begin{array}{ll}\text { twkm2 nu } & \text { ve } \\
\end{array}$ & $\begin{array}{l}62 \\
80 \\
\end{array}$ & $\begin{array}{l}73 \\
76 \\
\end{array}$ & $\begin{array}{l}101 \\
100 \\
\end{array}$ & $\begin{array}{l}98 \\
100\end{array}$ & $\begin{array}{l}95 \\
96 \\
\end{array}$ & nu vé & ve: I \\
\hline & $\begin{array}{ll}\text { twkm3 nu } & \text { ve } \\
\end{array}$ & $\begin{array}{l}59 \\
62\end{array}$ & $\begin{array}{l}71 \\
74\end{array}$ & $\begin{array}{l}93 \\
96\end{array}$ & $\begin{array}{l}92 \\
98\end{array}$ & $\begin{array}{l}90 \\
94\end{array}$ & nu vé & ve: I \\
\hline & $\begin{array}{c}12 \_1 \quad \text { nu } \\
\text { (vă)zut }\end{array}$ & $\begin{array}{l}\mathbf{5 2} \\
28 \\
\end{array}$ & $\begin{array}{l}80 \\
62 \\
\end{array}$ & $\begin{array}{l}97 \\
70 \\
\end{array}$ & $\begin{array}{l}95 \\
69 \\
\end{array}$ & $\begin{array}{l}92 \\
68 \\
\end{array}$ & 'nu zút & nu: D, I, F0 \\
\hline & $\begin{array}{c}12 \_\mathrm{nu} \\
\text { (vă)zut }\end{array}$ & $\begin{array}{l}49 \\
26 \\
\end{array}$ & $\begin{array}{l}80 \\
61 \\
\end{array}$ & $\begin{array}{l}97 \\
69 \\
\end{array}$ & $\begin{array}{l}95 \\
69 \\
\end{array}$ & $\begin{array}{l}92 \\
68 \\
\end{array}$ & 'nu zút & nu: $\mathrm{D}, \mathrm{I}, \mathrm{F} 0$ \\
\hline & $\begin{array}{l}\text { 14_1 n-am } \\
\text { (vă)zut }\end{array}$ & $\begin{array}{l}89 \\
71 \\
\end{array}$ & $\begin{array}{l}76 \\
66 \\
\end{array}$ & $\begin{array}{l}\mathbf{1 0 4} \\
82 \\
\end{array}$ & $\begin{array}{l}\mathbf{1 0 1} \\
80\end{array}$ & $\begin{array}{l}96 \\
72 \\
\end{array}$ & 'n-am zút & n-am: I, F0 \\
\hline & $\begin{array}{l}\text { 14_2 n-am } \\
\text { (vă)zut }\end{array}$ & $\begin{array}{l}86 \\
55 \\
\end{array}$ & $\begin{array}{l}76 \\
66 \\
\end{array}$ & $\begin{array}{l}\mathbf{1 0 4} \\
81\end{array}$ & $\begin{array}{l}\mathbf{1 0 1} \\
81\end{array}$ & $\begin{array}{l}97 \\
79 \\
\end{array}$ & 'n-am zút & n-am: D, I, F0 \\
\hline & $\begin{array}{l}14 \_3 \text { n-am } \\
\text { (vă)zut }\end{array}$ & $\begin{array}{l}95 \\
78\end{array}$ & $\begin{array}{l}76 \\
66\end{array}$ & $\begin{array}{l}\mathbf{1 0 4} \\
82\end{array}$ & $\begin{array}{l}100 \\
80\end{array}$ & $\begin{array}{l}96 \\
73\end{array}$ & 'n-am zút & n-am: I, F0 \\
\hline
\end{tabular}




\begin{tabular}{|c|c|c|c|c|c|c|c|c|}
\hline \multirow[t]{9}{*}{ BM5 } & $\begin{array}{c}\text { twkm1 nu } \\
\text { ve }\end{array}$ & $\begin{array}{l}74 \\
98\end{array}$ & $\begin{array}{l}74 \\
78\end{array}$ & $\begin{array}{l}174 \\
202\end{array}$ & $\begin{array}{l}181 \\
205\end{array}$ & $\begin{array}{l}179 \\
211\end{array}$ & nù "ve & ve: I, F0 \\
\hline & $\begin{array}{ll}\text { twkm2 nu } & \text { ve } \\
\end{array}$ & $\begin{array}{l}63 \\
94\end{array}$ & $\begin{array}{l}75 \\
80\end{array}$ & $\begin{array}{l}178 \\
175\end{array}$ & $\begin{array}{l}178 \\
169\end{array}$ & $\begin{array}{l}173 \\
167\end{array}$ & nu "ve & ve: D, I \\
\hline & $\begin{array}{ll}\text { twkm3 nu } & \text { ve } \\
& \text { ve }\end{array}$ & $\begin{array}{l}63 \\
107\end{array}$ & $\begin{array}{l}80 \\
80\end{array}$ & $\begin{array}{l}196 \\
\mathbf{2 4 2}\end{array}$ & $\begin{array}{l}219 \\
\mathbf{2 3 7}\end{array}$ & $\begin{array}{l}228 \\
245\end{array}$ & nù "ve & ve: $\mathrm{D}, \mathrm{F} 0$ \\
\hline & $\begin{array}{c}12 \_1 \text { nu } \\
\text { (vă)zut }\end{array}$ & $\begin{array}{l}\mathbf{8 3} \\
50\end{array}$ & $\begin{array}{l}\mathbf{8 1} \\
70\end{array}$ & $\begin{array}{l}\mathbf{2 6 9} \\
173\end{array}$ & $\begin{array}{l}\mathbf{2 8 1} \\
168\end{array}$ & $\begin{array}{l}260 \\
166\end{array}$ & "nu zút & nu: D, I, F0 \\
\hline & $\begin{array}{c}12 \_ \text {nu } \\
\text { (vă)zut }\end{array}$ & $\begin{array}{l}73 \\
51\end{array}$ & $\begin{array}{l}79 \\
80\end{array}$ & $\begin{array}{l}300 \\
193 \\
\end{array}$ & $\begin{array}{l}\mathbf{3 1 9} \\
192\end{array}$ & $\begin{array}{l}299 \\
188\end{array}$ & "nu zút & $\begin{array}{l}\text { nu: } \mathrm{D}, \mathrm{F} 0 \\
\text { ve: I }\end{array}$ \\
\hline & $\begin{array}{c}12 \_3 \mathrm{nu} \\
\text { (vă)zut }\end{array}$ & $\begin{array}{l}62 \\
56 \\
\end{array}$ & $\begin{array}{l}76 \\
74 \\
\end{array}$ & $\begin{array}{l}\mathbf{2 8 9} \\
194 \\
\end{array}$ & $\begin{array}{l}308 \\
187 \\
\end{array}$ & $\begin{array}{l}296 \\
182 \\
\end{array}$ & "nu zút & nu: I, F0 \\
\hline & $\begin{array}{l}\text { 14_1 n-am } \\
\text { (vă)zut }\end{array}$ & $\begin{array}{l}93 \\
78\end{array}$ & $\begin{array}{l}81 \\
74\end{array}$ & $\begin{array}{l}\mathbf{2 8 1} \\
185\end{array}$ & $\begin{array}{l}\mathbf{2 9 6} \\
181\end{array}$ & $\begin{array}{l}\mathbf{2 6 9} \\
171\end{array}$ & "n-am zút & n-am: I, F0 \\
\hline & $\begin{array}{l}\text { 14_2 n-am } \\
\text { (vă)zut }\end{array}$ & $\begin{array}{l}\mathbf{8 1} \\
51\end{array}$ & $\begin{array}{l}77 \\
67\end{array}$ & $\begin{array}{l}\mathbf{2 0 2} \\
179\end{array}$ & $\begin{array}{l}\mathbf{1 8 2} \\
170\end{array}$ & $\begin{array}{l}168 \\
168\end{array}$ & "n-am zút & n-am: D, I, F0 \\
\hline & $\begin{array}{l}143 \text { n-am } \\
\text { (vă)zut }\end{array}$ & $\begin{array}{l}91 \\
53\end{array}$ & $\begin{array}{l}82 \\
68\end{array}$ & $\begin{array}{l}243 \\
158\end{array}$ & $\begin{array}{l}\mathbf{2 0 7} \\
157\end{array}$ & $\begin{array}{l}\mathbf{1 7 2} \\
156\end{array}$ & "n-am zút & n-am: D, I, F0 \\
\hline \multirow[t]{6}{*}{ BM6 } & $\begin{array}{c}\text { twkm1 nu } \\
\text { ve }\end{array}$ & $\begin{array}{l}45 \\
81\end{array}$ & $\begin{array}{l}80 \\
83\end{array}$ & $\begin{array}{l}137 \\
149 \\
\end{array}$ & $\begin{array}{l}138 \\
\mathbf{1 5 8} \\
\end{array}$ & $\begin{array}{l}138 \\
156\end{array}$ & "nu vé & ve: D, I, F0 \\
\hline & $\begin{array}{ll}\text { twkm2 nu } \\
\\
\text { ve }\end{array}$ & $\begin{array}{l}53 \\
95 \\
\end{array}$ & $\begin{array}{l}79 \\
83 \\
\end{array}$ & $\begin{array}{l}137 \\
148 \\
\end{array}$ & $\begin{array}{l}138 \\
\mathbf{1 5 8} \\
\end{array}$ & $\begin{array}{l}136 \\
\mathbf{1 5 4}\end{array}$ & nu "ve & ve: D, I, F0 \\
\hline & $\begin{array}{ll}\text { twkm3 nu } & \text { ne } \\
& \text { ve }\end{array}$ & $\begin{array}{l}37 \\
86\end{array}$ & $\begin{array}{l}80 \\
83\end{array}$ & $\begin{array}{l}137 \\
150 \\
\end{array}$ & $\begin{array}{l}138 \\
\mathbf{1 5 8}\end{array}$ & $\begin{array}{l}140 \\
156\end{array}$ & nu "ve & ve: $\mathrm{D}, \mathrm{I}, \mathrm{F} 0$ \\
\hline & $\begin{array}{l}\text { 12_1 nu } \\
\text { (vă)zut }\end{array}$ & $\begin{array}{l}73 \\
72\end{array}$ & $\begin{array}{l}85 \\
82\end{array}$ & $\begin{array}{l}\mathbf{1 4 8} \\
127\end{array}$ & $\begin{array}{l}\mathbf{1 5 7} \\
134\end{array}$ & $\begin{array}{l}\mathbf{1 6 8} \\
128\end{array}$ & "nu zút & nu: I, F0 \\
\hline & $\begin{array}{c}12 \_ \text {nu } \\
\text { (vă)zut }\end{array}$ & $\begin{array}{l}64 \\
84\end{array}$ & $\begin{array}{l}85 \\
80\end{array}$ & $\begin{array}{l}\mathbf{1 5 0} \\
131\end{array}$ & $\begin{array}{l}\mathbf{1 5 7} \\
134\end{array}$ & $\begin{array}{l}166 \\
122\end{array}$ & "nu zút & nu: I, F0 \\
\hline & $\begin{array}{l}\text { 14_3 n-am } \\
\text { (vă)zut }\end{array}$ & $\begin{array}{l}107 \\
63\end{array}$ & $\begin{array}{l}82 \\
77\end{array}$ & $\begin{array}{l}\mathbf{1 3 4} \\
115\end{array}$ & $\begin{array}{l}\mathbf{1 3 9} \\
112\end{array}$ & $\begin{array}{l}\mathbf{1 4 1} \\
109\end{array}$ & "n-am zút & n-am: D, I, F0 \\
\hline \multirow[t]{4}{*}{ Cr5 } & $\begin{array}{l}\text { twkm1 nu } \\
\text { ve }\end{array}$ & $\begin{array}{l}68 \\
61\end{array}$ & $\begin{array}{l}85 \\
83\end{array}$ & $\begin{array}{l}228 \\
229\end{array}$ & $\begin{array}{l}236 \\
213\end{array}$ & $\begin{array}{l}234 \\
201\end{array}$ & "nu vé & nu: I, F0 \\
\hline & $\begin{array}{rr}\text { twkm2 nu } & \begin{array}{l}\text { ve } \\
\text { ve }\end{array} \\
\end{array}$ & $\begin{array}{l}42 \\
74 \\
\end{array}$ & $\begin{array}{l}80 \\
86\end{array}$ & $\begin{array}{l}201 \\
194 \\
\end{array}$ & $\begin{array}{l}196 \\
201 \\
\end{array}$ & $\begin{array}{l}192 \\
209 \\
\end{array}$ & nu "ve & ve: D, I \\
\hline & $\begin{array}{ll}\text { twkm3 nu } & \begin{array}{l}\text { ne } \\
\text { ve }\end{array} \\
\end{array}$ & $\begin{array}{l}41 \\
\mathbf{5 7} \\
\end{array}$ & $\begin{array}{l}78 \\
83\end{array}$ & $\begin{array}{l}201 \\
196 \\
\end{array}$ & $\begin{array}{l}195 \\
193\end{array}$ & $\begin{array}{l}193 \\
186 \\
\end{array}$ & nu vé & ve: D, I \\
\hline & $\begin{array}{c}12 \_1 \text { nu } \\
\text { (vă)zut }\end{array}$ & $\begin{array}{l}84 \\
52 \\
\end{array}$ & $\begin{array}{l}73 \\
61\end{array}$ & $\begin{array}{l}216 \\
216 \\
\end{array}$ & $\begin{array}{l}230 \\
211\end{array}$ & $\begin{array}{l}240 \\
206\end{array}$ & 'nu /"nu zút & nu: D, I, F0 \\
\hline
\end{tabular}




\begin{tabular}{|c|c|c|c|c|c|c|c|c|}
\hline & $\begin{array}{c}12 \_ \text {nu } \\
\text { (vă)zut }\end{array}$ & $\begin{array}{l}55 \\
48\end{array}$ & $\begin{array}{l}77 \\
63\end{array}$ & $\begin{array}{l}237 \\
222\end{array}$ & $\begin{array}{l}240 \\
224\end{array}$ & $\begin{array}{l}240 \\
212\end{array}$ & 'nu zút & nu: I, F0 \\
\hline & $\begin{array}{l}12 \_3 \quad \text { nu } \\
\text { (vă)zut }\end{array}$ & $\begin{array}{l}48 \\
31\end{array}$ & $\begin{array}{l}72 \\
55\end{array}$ & $\begin{array}{l}211 \\
193\end{array}$ & $\begin{array}{l}\mathbf{2 1 3} \\
193\end{array}$ & $\begin{array}{c}211 \\
194\end{array}$ & 'nu zút & nu: D, I, F0 \\
\hline & $\begin{array}{c}12 \_5 \text { nu } \\
\text { (vă)zut }\end{array}$ & $\begin{array}{l}40 \\
56\end{array}$ & $\begin{array}{l}72 \\
64\end{array}$ & $\begin{array}{l}213 \\
199\end{array}$ & $\begin{array}{l}216 \\
202\end{array}$ & $\begin{array}{l}217 \\
203\end{array}$ & 'nu zút & $\begin{array}{l}\text { nu: I } \\
\text { zut: D }\end{array}$ \\
\hline & $\begin{array}{c}12 \text { 6 nu } \\
\text { (vă)zut }\end{array}$ & $\begin{array}{l}47 \\
54\end{array}$ & $\begin{array}{l}76 \\
65\end{array}$ & $\begin{array}{l}\mathbf{2 1 4} \\
196\end{array}$ & $\begin{array}{l}215 \\
194\end{array}$ & $\begin{array}{l}\mathbf{2 1 8} \\
191\end{array}$ & 'nu zút & $\begin{array}{l}\text { nu: I, F0 } \\
\text { vc }\end{array}$ \\
\hline \multirow[t]{9}{*}{ Cr6 } & $\begin{array}{ll}\text { twkm1 nu } & \text { ve } \\
\end{array}$ & $\begin{array}{l}77 \\
66\end{array}$ & $\begin{array}{l}\mathbf{8 3} \\
82\end{array}$ & $\begin{array}{l}115 \\
129\end{array}$ & $\begin{array}{l}116 \\
131\end{array}$ & $\begin{array}{l}116 \\
123\end{array}$ & nù vé & $\begin{array}{l}\text { nu: I } \\
\text { ve: F0 (2) }\end{array}$ \\
\hline & $\begin{array}{ll}\text { twkm2 } & \text { nu } \\
& \text { ve }\end{array}$ & $\begin{array}{l}66 \\
68\end{array}$ & $\begin{array}{l}82 \\
83\end{array}$ & $\begin{array}{l}115 \\
122\end{array}$ & $\begin{array}{l}117 \\
123\end{array}$ & $\begin{array}{l}116 \\
117\end{array}$ & nu vé & ve: I \\
\hline & $\begin{array}{ll}\text { twkm3 } & \text { nu } \\
& \text { ve }\end{array}$ & $\begin{array}{l}67 \\
66\end{array}$ & $\begin{array}{l}79 \\
81\end{array}$ & $\begin{array}{l}106 \\
\mathbf{1 3 6}\end{array}$ & $\begin{array}{l}107 \\
\mathbf{1 3 4}\end{array}$ & $\begin{array}{l}108 \\
127\end{array}$ & nu vé & ve: I, F0 \\
\hline & $\begin{array}{c}12 \_1 \text { nu } \\
\text { (vă)zut }\end{array}$ & $\begin{array}{l}91 \\
84\end{array}$ & $\begin{array}{l}77 \\
77 \\
\end{array}$ & $\begin{array}{l}133 \\
141 \\
\end{array}$ & $\begin{array}{l}132 \\
141\end{array}$ & $\begin{array}{l}143 \\
137\end{array}$ & 'nu zút & \\
\hline & $\begin{array}{l}12 \_ \text {nu } \\
\text { (vă)zut }\end{array}$ & $\begin{array}{l}64 \\
44\end{array}$ & $\begin{array}{l}77 \\
75\end{array}$ & $\begin{array}{l}\mathbf{1 4 1} \\
118\end{array}$ & $\begin{array}{l}144 \\
119\end{array}$ & $\begin{array}{l}\mathbf{1 3 8} \\
118\end{array}$ & "nu zút & nu: I, F0 \\
\hline & $\begin{array}{c}12 \_ \text {nu } \\
\text { (vă)zut }\end{array}$ & $\begin{array}{l}72 \\
67 \\
\end{array}$ & $\begin{array}{l}75 \\
67\end{array}$ & $\begin{array}{l}\mathbf{1 5 8} \\
103\end{array}$ & $\begin{array}{l}\mathbf{1 6 6} \\
100 \\
\end{array}$ & $\begin{array}{l}159 \\
98\end{array}$ & "nu zút & nu: I, F0 \\
\hline & $\begin{array}{l}\text { 14_1 n-am } \\
\text { (vă)zut }\end{array}$ & $\begin{array}{l}114 \\
74\end{array}$ & $\begin{array}{l}78 \\
66\end{array}$ & $\begin{array}{l}149 \\
101\end{array}$ & $\begin{array}{l}166 \\
98\end{array}$ & $\begin{array}{l}157 \\
96\end{array}$ & "n-am zút & $\begin{array}{l}\text { n-am: } \mathrm{D}, \mathrm{I}, \\
\text { F0 }\end{array}$ \\
\hline & $\begin{array}{l}\text { 14_2 n-am } \\
\text { (vă)zut }\end{array}$ & $\begin{array}{l}94 \\
77\end{array}$ & $\begin{array}{l}82 \\
70\end{array}$ & $\begin{array}{l}\mathbf{1 7 0} \\
104\end{array}$ & $\begin{array}{l}172 \\
99\end{array}$ & $\begin{array}{l}154 \\
98\end{array}$ & "n-am zút & n-am: I, F0 \\
\hline & $\begin{array}{l}\text { 14_3 n-am } \\
\text { (vă)zut }\end{array}$ & $\begin{array}{l}96 \\
74\end{array}$ & $\begin{array}{l}\mathbf{8 1} \\
71\end{array}$ & $\begin{array}{l}162 \\
96\end{array}$ & $\begin{array}{l}\mathbf{1 5 6} \\
91\end{array}$ & $\begin{array}{l}119 \\
95\end{array}$ & "n-am zút & n-am: I, F0 \\
\hline \multirow[t]{7}{*}{ Cs5 } & $\begin{array}{c}\text { twkm1 nu } \\
\text { ve }\end{array}$ & $\begin{array}{l}82 \\
94\end{array}$ & $\begin{array}{l}69 \\
70\end{array}$ & $\begin{array}{l}174 \\
175\end{array}$ & $\begin{array}{l}170 \\
168\end{array}$ & $\begin{array}{l}166 \\
166\end{array}$ & nu vé & ve: I \\
\hline & $\begin{array}{ll}\text { twkm2 } & \text { nu } \\
& \text { ve }\end{array}$ & $\begin{array}{l}113 \\
115\end{array}$ & $\begin{array}{l}74 \\
71\end{array}$ & $\begin{array}{l}168 \\
178\end{array}$ & $\begin{array}{l}169 \\
159\end{array}$ & $\begin{array}{l}162 \\
154\end{array}$ & nù vé & nu: I \\
\hline & $\begin{array}{ll}\text { twkm3 nu } & \text { ve } \\
& \text { ve }\end{array}$ & $\begin{array}{l}142 \\
101\end{array}$ & $\begin{array}{l}69 \\
70\end{array}$ & $\begin{array}{l}184 \\
175\end{array}$ & $\begin{array}{l}\mathbf{1 8 4} \\
168\end{array}$ & $\begin{array}{l}168 \\
165\end{array}$ & nú vé & $\begin{array}{l}\text { nu: D, F0 (2) } \\
\text { ve: I }\end{array}$ \\
\hline & $\begin{array}{c}12 \_1 \quad \text { nu } \\
\text { (vă)zut }\end{array}$ & $\begin{array}{l}64 \\
61 \\
\end{array}$ & $\begin{array}{l}81 \\
70\end{array}$ & $\begin{array}{l}277 \\
168 \\
\end{array}$ & $\begin{array}{l}264 \\
160\end{array}$ & $\begin{array}{l}233 \\
177\end{array}$ & "nu zút & $\begin{array}{l}\text { nu: I, F0 } \\
\text { zut: I }\end{array}$ \\
\hline & $\begin{array}{l}14 \text { 1 n-am } \\
\text { (vă)zut }\end{array}$ & $\begin{array}{l}143 \\
103\end{array}$ & $\begin{array}{l}72 \\
74\end{array}$ & $\begin{array}{l}177 \\
\mathbf{2 1 0}\end{array}$ & $\begin{array}{l}193 \\
212\end{array}$ & $\begin{array}{l}212 \\
211\end{array}$ & "n-am zút & $\begin{array}{l}\text { n-am: } \mathrm{D}, \mathrm{F} 0 \\
\text { nivel maxim } \\
\text { pe } m \text {; ve: } \mathrm{I}, \mathrm{F} 0\end{array}$ \\
\hline & $\begin{array}{l}\text { 14_2 n-am } \\
\text { (vă)zut }\end{array}$ & $\begin{array}{l}125 \\
74\end{array}$ & $\begin{array}{l}77 \\
75\end{array}$ & $\begin{array}{l}225 \\
221\end{array}$ & $\begin{array}{l}\mathbf{2 5 6} \\
227\end{array}$ & $\begin{array}{l}\mathbf{2 5 5} \\
217\end{array}$ & "n-am zút & n-am: D; I, F0 \\
\hline & $\begin{array}{l}\text { 14_3 n-am } \\
\text { (vă)zut }\end{array}$ & $\begin{array}{l}112 \\
97\end{array}$ & $\begin{array}{l}79 \\
67\end{array}$ & $\begin{array}{l}218 \\
176\end{array}$ & $\begin{array}{l}231 \\
168\end{array}$ & $\begin{array}{l}\mathbf{2 3 5} \\
172\end{array}$ & "n-am zút & n-am: I, F0 \\
\hline
\end{tabular}




\begin{tabular}{|c|c|c|c|c|c|c|c|c|}
\hline \multirow[t]{6}{*}{ Cs6 } & $\begin{array}{ll}\text { twkm1 nu } \\
\text { ve }\end{array}$ & $\begin{array}{l}113 \\
120\end{array}$ & $\begin{array}{l}\mathbf{8 1} \\
80\end{array}$ & $\begin{array}{l}\mathbf{1 3 8} \\
117\end{array}$ & $\begin{array}{l}\mathbf{1 5 0} \\
120\end{array}$ & $\begin{array}{l}130 \\
131\end{array}$ & "nu vé & nu: I, F0 \\
\hline & $\begin{array}{ll}\text { twkm2 nu } \\
\text { ve }\end{array}$ & $\begin{array}{l}\mathbf{1 4 7} \\
115\end{array}$ & $\begin{array}{l}78 \\
78\end{array}$ & $\begin{array}{l}123 \\
118 \\
\end{array}$ & $\begin{array}{l}142 \\
128\end{array}$ & $\begin{array}{l}139 \\
134\end{array}$ & "nu vé & nu: D, F0(2) \\
\hline & $\begin{array}{ll}\text { twkm3 nu } & \begin{array}{l}\text { ne } \\
\text { ve }\end{array} \\
\end{array}$ & $\begin{array}{l}124 \\
121 \\
\end{array}$ & $\begin{array}{l}\mathbf{8 2} \\
79 \\
\end{array}$ & $\begin{array}{l}\mathbf{1 4 0} \\
115 \\
\end{array}$ & $\begin{array}{l}\mathbf{1 6 4} \\
119 \\
\end{array}$ & $\begin{array}{l}\mathbf{1 8 7} \\
132 \\
\end{array}$ & "nu vé & nu: I, F0 \\
\hline & $\begin{array}{c}12 \_1 \quad n u \\
\text { (vă)zut }\end{array}$ & $\begin{array}{l}55 \\
65 \\
\end{array}$ & $\begin{array}{l}84 \\
64 \\
\end{array}$ & $\begin{array}{l}\mathbf{1 6 3} \\
86 \\
\end{array}$ & $\begin{array}{l}\mathbf{1 5 0} \\
88 \\
\end{array}$ & $\begin{array}{l}\mathbf{1 3 6} \\
86 \\
\end{array}$ & "nu zút & nu: I, F0 \\
\hline & $\begin{array}{c}12 \_ \text {nu } \\
\text { (vă)zut }\end{array}$ & $\begin{array}{l}59 \\
65 \\
\end{array}$ & $\begin{array}{l}81 \\
67 \\
\end{array}$ & $\begin{array}{l}230 \\
93 \\
\end{array}$ & $\begin{array}{l}225 \\
92 \\
\end{array}$ & $\begin{array}{l}199 \\
91 \\
\end{array}$ & "nu zút & nu: I, F0 \\
\hline & $\begin{array}{l}\text { 14_1no-am } \\
\text { (vă)zut }\end{array}$ & $\begin{array}{l}\mathbf{1 0 9} \\
62\end{array}$ & $\begin{array}{l}81 \\
68\end{array}$ & $\begin{array}{l}\mathbf{1 4 6} \\
95\end{array}$ & $\begin{array}{l}147 \\
93\end{array}$ & $\begin{array}{l}\mathbf{1 3 3} \\
98\end{array}$ & "no-am zút & no-am: D, I, F0 \\
\hline \multirow{8}{*}{ Iș5 } & $\begin{array}{cc}\text { twkm1 nu } \\
\\
\text { ve }\end{array}$ & $\begin{array}{l}72 \\
97\end{array}$ & $\begin{array}{l}74 \\
75\end{array}$ & $\begin{array}{l}255 \\
244\end{array}$ & $\begin{array}{l}\mathbf{2 5 5} \\
239\end{array}$ & $\begin{array}{l}243 \\
244\end{array}$ & nù vé & $\begin{array}{l}\text { nu: } F 0(2) \\
\text { ve: I }\end{array}$ \\
\hline & $\begin{array}{ll}\text { twkm2 } & \text { nu } \\
& \text { ve }\end{array}$ & $\begin{array}{l}78 \\
88 \\
\end{array}$ & $\begin{array}{l}74 \\
75 \\
\end{array}$ & $\begin{array}{l}231 \\
230 \\
\end{array}$ & $\begin{array}{l}\mathbf{2 3 5} \\
218 \\
\end{array}$ & $\begin{array}{l}232 \\
219 \\
\end{array}$ & nù vé & $\begin{array}{l}\text { nu: F0(2) } \\
\text { ve: I }\end{array}$ \\
\hline & $\begin{array}{ll}\text { twkm3 nu } & \begin{array}{l}\text { ne } \\
\text { ve }\end{array} \\
\end{array}$ & $\begin{array}{l}91 \\
92 \\
\end{array}$ & $\begin{array}{l}73 \\
77 \\
\end{array}$ & $\begin{array}{l}223 \\
232 \\
\end{array}$ & $\begin{array}{l}227 \\
220 \\
\end{array}$ & $\begin{array}{l}219 \\
224 \\
\end{array}$ & nu vé & ve: I \\
\hline & $\begin{array}{c}12 \text { _1 nu } \\
\text { (vă)zut }\end{array}$ & $\begin{array}{l}57 \\
49 \\
\end{array}$ & $\begin{array}{l}70 \\
67 \\
\end{array}$ & $\begin{array}{l}\mathbf{2 8 9} \\
182 \\
\end{array}$ & $\begin{array}{l}307 \\
180 \\
\end{array}$ & $\begin{array}{l}\mathbf{3 0 4} \\
175 \\
\end{array}$ & "nu zút & nu: I, F0 \\
\hline & $\begin{array}{l}12 \_ \text {nu } \\
\text { (vă)zut }\end{array}$ & $\begin{array}{l}68 \\
62 \\
\end{array}$ & $\begin{array}{l}72 \\
63 \\
\end{array}$ & $\begin{array}{l}237 \\
181 \\
\end{array}$ & $\begin{array}{l}269 \\
174 \\
\end{array}$ & $\begin{array}{l}289 \\
169 \\
\end{array}$ & "nu zút & nu: I, F0 \\
\hline & $\begin{array}{c}12 \_3 \text { nu } \\
\text { (vă)zut }\end{array}$ & $\begin{array}{l}69 \\
50 \\
\end{array}$ & $\begin{array}{l}71 \\
65 \\
\end{array}$ & $\begin{array}{l}\mathbf{2 5 1} \\
172 \\
\end{array}$ & $\begin{array}{l}287 \\
168 \\
\end{array}$ & $\begin{array}{l}299 \\
164 \\
\end{array}$ & "nu zút & nu: D, I, F0 \\
\hline & $\begin{array}{l}\text { 14_1 n-am } \\
\text { (vă)zut }\end{array}$ & $\begin{array}{l}81 \\
48 \\
\end{array}$ & $\begin{array}{l}73 \\
70 \\
\end{array}$ & $\begin{array}{l}\mathbf{2 6 9} \\
218 \\
\end{array}$ & $\begin{array}{l}\mathbf{2 8 7} \\
217 \\
\end{array}$ & $\begin{array}{l}306 \\
215 \\
\end{array}$ & "n-am zút & n-am: D, I, F0 \\
\hline & $\begin{array}{l}\text { 14_2 n-am } \\
\text { (vă)zut }\end{array}$ & $\begin{array}{l}95 \\
58 \\
\end{array}$ & $\begin{array}{l}74 \\
65 \\
\end{array}$ & $\begin{array}{l}259 \\
194 \\
\end{array}$ & $\begin{array}{l}278 \\
185 \\
\end{array}$ & $\begin{array}{l}294 \\
181 \\
\end{array}$ & "n-am zút & n-am: D, I, F0 \\
\hline \multirow{7}{*}{ Iș6 } & $\begin{array}{ll}\text { twkm1 nu } & \begin{array}{l}\text { ve } \\
\text { ve }\end{array} \\
\end{array}$ & $\begin{array}{l}74 \\
86 \\
\end{array}$ & $\begin{array}{l}69 \\
74 \\
\end{array}$ & $\begin{array}{l}118 \\
111 \\
\end{array}$ & $\begin{array}{l}114 \\
106 \\
\end{array}$ & $\begin{array}{l}107 \\
101 \\
\end{array}$ & nu vé & ve: I \\
\hline & $\begin{array}{ll}\text { twkm2 nu } \\
\\
\text { ve }\end{array}$ & $\begin{array}{l}62 \\
93 \\
\end{array}$ & $\begin{array}{l}71 \\
76 \\
\end{array}$ & $\begin{array}{l}120 \\
112 \\
\end{array}$ & $\begin{array}{l}120 \\
110 \\
\end{array}$ & $\begin{array}{l}115 \\
103 \\
\end{array}$ & nu vé & ve: I \\
\hline & $\begin{array}{ll}\text { twkm3 nu } & \begin{array}{l}\text { ne } \\
\text { ve }\end{array} \\
\end{array}$ & $\begin{array}{l}91 \\
88 \\
\end{array}$ & $\begin{array}{l}73 \\
77 \\
\end{array}$ & $\begin{array}{l}127 \\
116 \\
\end{array}$ & $\begin{array}{l}124 \\
113 \\
\end{array}$ & $\begin{array}{l}115 \\
109 \\
\end{array}$ & nu vé & ve: I \\
\hline & $\begin{array}{c}12 \text { 1 nu } \\
\text { (vă)zut }\end{array}$ & $\begin{array}{l}53 \\
104 \\
\end{array}$ & $\begin{array}{l}76 \\
74 \\
\end{array}$ & $\begin{array}{l}\mathbf{1 7 2} \\
112 \\
\end{array}$ & $\begin{array}{l}\mathbf{1 7 1} \\
108 \\
\end{array}$ & $\begin{array}{l}\mathbf{1 6 7} \\
106 \\
\end{array}$ & "nu zút & $\begin{array}{l}\text { nu: I, F0 } \\
\text { ve: } D\end{array}$ \\
\hline & $\begin{array}{c}12 \_ \text {nu } \\
\text { (vă)zut }\end{array}$ & $\begin{array}{l}91 \\
99 \\
\end{array}$ & $\begin{array}{l}\mathbf{8 1} \\
74 \\
\end{array}$ & $\begin{array}{l}\mathbf{1 5 6} \\
105 \\
\end{array}$ & $\begin{array}{l}\mathbf{1 5 2} \\
101 \\
\end{array}$ & $\begin{array}{l}144 \\
104 \\
\end{array}$ & "nu zút & ve: I, F0 \\
\hline & $\begin{array}{l}12 \text { 3 nu } \\
\text { (vă)zut }\end{array}$ & $\begin{array}{l}94 \\
80 \\
\end{array}$ & $\begin{array}{l}74 \\
71 \\
\end{array}$ & $\begin{array}{l}125 \\
113 \\
\end{array}$ & $\begin{array}{l}124 \\
114 \\
\end{array}$ & $\begin{array}{l}123 \\
112 \\
\end{array}$ & "nu zút & nu: I \\
\hline & $14 \_1 \mathrm{n}-\mathrm{am}$ & 92 & 79 & 145 & 154 & 157 & "n-am zút & n-am: I, F0 \\
\hline
\end{tabular}




\begin{tabular}{|c|c|c|c|c|c|c|c|c|}
\hline & (vă)zut & 77 & 71 & 115 & 100 & 113 & & \\
\hline & 14_2 n-am & 133 & 79 & 161 & 161 & 149 & "n-am zút & n-am: D, I, F0 \\
\hline & (vă)zut & 77 & 72 & 114 & 105 & 103 & & \\
\hline & $\begin{array}{l}\text { 14_3 n-am } \\
\text { (vă)zut }\end{array}$ & $\begin{array}{l}132 \\
77\end{array}$ & $\begin{array}{l}\mathbf{8 1} \\
72\end{array}$ & $\begin{array}{l}\mathbf{1 8 6} \\
107\end{array}$ & $\begin{array}{l}\mathbf{1 7 1} \\
100\end{array}$ & $\begin{array}{l}\mathbf{1 4 6} \\
108\end{array}$ & "n-am zút & n-am: D, I, F0 \\
\hline T5 & twkm1 nu & 54 & 71 & 189 & 185 & 190 & nu "ve & ve: I, F0 \\
\hline & ve & 77 & 80 & 208 & 218 & 221 & & \\
\hline & twkm2 nu & 49 & 68 & 180 & 178 & 177 & nu "ve & ve: I, F0 \\
\hline & ve & 64 & 75 & 197 & 204 & 206 & & \\
\hline & twkm3 nu & 61 & 73 & 176 & 173 & 174 & nu "ve & ve: I, F0 \\
\hline & & 73 & 80 & 190 & 200 & 203 & & \\
\hline & 12_1 nu & 66 & 71 & 233 & 239 & 239 & 'nu/"nu zút & nu: D, I, F0 \\
\hline & (vă)zut & 45 & 68 & 197 & 201 & 195 & & \\
\hline & $12 \_2 \mathrm{nu}$ & 67 & 76 & 246 & 255 & 260 & "nu zút & nu: I, F0 \\
\hline & (vă)zut & 71 & 74 & 211 & 218 & 215 & & \\
\hline & $123 \mathrm{nu}$ & 53 & 78 & 236 & 239 & 242 & 'nu zút & nu: F0 \\
\hline & (vă)zut & 64 & 79 & 207 & 216 & 219 & & zut: I \\
\hline & 141 n-am & 89 & 75 & 278 & 271 & 244 & "n-am zút & n-am: $\quad \mathrm{D}, \quad \mathrm{I}$, \\
\hline & (vă)zut & 65 & 71 & 162 & 160 & 157 & & F0 \\
\hline & 142 n-am & 99 & 82 & 264 & 269 & 261 & "n-am zút & n-am: $\quad$ D, $\quad$ I, \\
\hline & (vă)zut & 75 & 76 & 169 & 171 & 166 & & F0 \\
\hline & 143 n-am & 84 & 80 & 228 & 237 & 248 & "n-am zút & n-am:F0(3) \\
\hline & (vă)zut & 82 & 80 & 237 & 236 & 222 & & ni-vel maxim \\
\hline & & & & & & & & pe $m$ \\
\hline T6 & twkm1 nu & 73 & 68 & 93 & 93 & 90 & nu "ve & ve. I \\
\hline & ve & 85 & 78 & 102 & 102 & 100 & & \\
\hline & twkm2 nu & 66 & 71 & 95 & 93 & 92 & nu "ve & ve: I, F0 (3) \\
\hline & ve & 73 & 77 & 107 & 107 & 107 & & \\
\hline & twkm3 nu & 75 & 71 & 94 & 94 & 94 & nu "ve & ve: I \\
\hline & ve & 86 & 81 & 105 & 106 & 107 & & \\
\hline & $12 \_1 \mathrm{nu}$ & 67 & 73 & 170 & 185 & 195 & "nu zút & nu: D, I, F0 \\
\hline & (vă)zut & 50 & 68 & 107 & 108 & 93 & & \\
\hline & $12 \_\mathrm{nu}$ & 68 & 79 & 149 & 162 & 168 & "nu zút & nu: I, F0 \\
\hline & (vă)zut & 77 & 77 & 111 & 108 & 97 & & \\
\hline & 12_3 nu & 60 & 76 & 153 & 163 & 170 & "nu zút & nu: I, F0 \\
\hline & (vă)zut & 56 & 69 & 107 & 104 & 92 & & \\
\hline & 14_1 n-am & 91 & 83 & 171 & 184 & 181 & "n-am zút & n-am: D, I, F0 \\
\hline & (vă)zut & 58 & 76 & 115 & 114 & 106 & & \\
\hline & 14_2n-am & 79 & 83 & 147 & 152 & 150 & "n-am zút & n-am: D, I, F0 \\
\hline & (vă)zut & 50 & 77 & 111 & 109 & 106 & & \\
\hline & 14_3 n-am & 87 & 81 & 175 & 190 & 185 & "n-am zút & n-am: I, F0 \\
\hline & (vă)zut & 70 & 75 & 114 & 111 & 102 & & \\
\hline
\end{tabular}


ANEXĂ: TABEL 2

\begin{tabular}{|c|c|c|c|c|c|c|c|c|}
\hline $\begin{array}{l}\text { Infor- } \\
\text { mator }\end{array}$ & Enunț & D & I & F0 (F1, & F2, & F3) & $\begin{array}{l}\text { Proeminență } \\
\text { auditivă }\end{array}$ & $\begin{array}{l}\text { Indici } \\
\text { acustici }\end{array}$ \\
\hline \multirow[t]{9}{*}{ B5 } & $\begin{array}{c}\text { twkm1 nu } \\
\text { ve }\end{array}$ & $\begin{array}{l}60 \\
70\end{array}$ & $\begin{array}{l}69 \\
75\end{array}$ & $\begin{array}{l}192 \\
191\end{array}$ & $\begin{array}{l}187 \\
190\end{array}$ & $\begin{array}{l}184 \\
184\end{array}$ & nu vé & ve: I \\
\hline & $\begin{array}{ll}\text { twkm2 } & \text { nu } \\
& \text { ve }\end{array}$ & $\begin{array}{l}62 \\
74\end{array}$ & $\begin{array}{l}75 \\
77\end{array}$ & $\begin{array}{l}207 \\
202\end{array}$ & $\begin{array}{l}201 \\
198\end{array}$ & $\begin{array}{l}194 \\
193\end{array}$ & nu vé & ve: I \\
\hline & $\begin{array}{ll}\text { twkm3 } & \text { nu } \\
& \text { ve }\end{array}$ & $\begin{array}{l}56 \\
68\end{array}$ & $\begin{array}{l}76 \\
78\end{array}$ & $\begin{array}{l}197 \\
199\end{array}$ & $\begin{array}{l}195 \\
196\end{array}$ & $\begin{array}{l}189 \\
189\end{array}$ & nu vé & ve: I \\
\hline & $\begin{array}{c}12 \text { 1 nu } \\
\text { (vă)zut }\end{array}$ & $\begin{array}{l}48 \\
50\end{array}$ & $\begin{array}{l}80 \\
71\end{array}$ & $\begin{array}{l}218 \\
170\end{array}$ & $\begin{array}{l}220 \\
169 \\
\end{array}$ & $\begin{array}{l}\mathbf{2 1 7} \\
156 \\
\end{array}$ & "nu zút & nu: I, F0 \\
\hline & $\begin{array}{l}12 \_\mathrm{nu} \\
\text { (vă)zut }\end{array}$ & $\begin{array}{l}49 \\
40\end{array}$ & $\begin{array}{l}\mathbf{8 0} \\
71\end{array}$ & $\begin{array}{l}217 \\
171\end{array}$ & $\begin{array}{l}219 \\
169\end{array}$ & $\begin{array}{l}\mathbf{2 1 7} \\
160\end{array}$ & "nu zút & nu: I, F0 \\
\hline & $\begin{array}{l}12 \_3 \mathrm{nu} \\
\text { (vă)zut }\end{array}$ & $\begin{array}{l}50 \\
41\end{array}$ & $\begin{array}{l}81 \\
73\end{array}$ & $\begin{array}{l}230 \\
171\end{array}$ & $\begin{array}{l}237 \\
170\end{array}$ & $\begin{array}{l}235 \\
168\end{array}$ & "nu zút & nu: I, F0 \\
\hline & $\begin{array}{l}14 \_1 \text { n-am } \\
\text { (vă)zut }\end{array}$ & $\begin{array}{l}83 \\
68 \\
\end{array}$ & $\begin{array}{l}79 \\
75 \\
\end{array}$ & $\begin{array}{l}\mathbf{2 0 0} \\
157 \\
\end{array}$ & $\begin{array}{l}\mathbf{2 0 0} \\
152 \\
\end{array}$ & $\begin{array}{l}194 \\
141 \\
\end{array}$ & "n-am zút & n-am: I, F0 \\
\hline & $\begin{array}{l}\text { 14_2 n-am } \\
\text { (vă)zut }\end{array}$ & $\begin{array}{l}74 \\
75\end{array}$ & $\begin{array}{l}\mathbf{8 0} \\
76\end{array}$ & $\begin{array}{l}200 \\
158\end{array}$ & $\begin{array}{l}\mathbf{2 0 0} \\
152\end{array}$ & $\begin{array}{l}194 \\
145\end{array}$ & "n-am zút & n-am: I, F0 \\
\hline & $\begin{array}{l}\text { 14_3 n-am } \\
\text { (vă)zut }\end{array}$ & $\begin{array}{l}72 \\
61 \\
\end{array}$ & $\begin{array}{l}81 \\
66 \\
\end{array}$ & $\begin{array}{l}233 \\
185 \\
\end{array}$ & $\begin{array}{l}\mathbf{2 3 9} \\
179 \\
\end{array}$ & $\begin{array}{l}241 \\
170 \\
\end{array}$ & "n-am zút & n-am: I, F0 \\
\hline \multirow[t]{8}{*}{ B6 } & $\begin{array}{ll}\text { twkm1 nu } & \text { ve } \\
\end{array}$ & $\begin{array}{l}65 \\
90\end{array}$ & $\begin{array}{l}75 \\
77\end{array}$ & $\begin{array}{l}96 \\
91\end{array}$ & $\begin{array}{l}92 \\
88\end{array}$ & $\begin{array}{l}88 \\
84\end{array}$ & nu vé & ve: $\mathrm{D}, \mathrm{I}$ \\
\hline & $\begin{array}{ll}\text { twkm2 } & \text { nu } \\
& \text { ve }\end{array}$ & $\begin{array}{l}62 \\
80\end{array}$ & $\begin{array}{l}73 \\
76\end{array}$ & $\begin{array}{l}101 \\
100\end{array}$ & $\begin{array}{l}98 \\
100\end{array}$ & $\begin{array}{l}95 \\
96\end{array}$ & nu vé & ve: I \\
\hline & $\begin{array}{ll}\text { twkm3 } & \text { nu } \\
& \text { ve }\end{array}$ & $\begin{array}{l}59 \\
62\end{array}$ & $\begin{array}{l}71 \\
74\end{array}$ & $\begin{array}{l}93 \\
96\end{array}$ & $\begin{array}{l}92 \\
98\end{array}$ & $\begin{array}{l}90 \\
94\end{array}$ & nu vé & ve: I \\
\hline & $\begin{array}{c}12 \_1 \text { nu } \\
\text { (vă)zut }\end{array}$ & $\begin{array}{l}\mathbf{5 2} \\
28\end{array}$ & $\begin{array}{l}80 \\
62\end{array}$ & $\begin{array}{l}97 \\
70\end{array}$ & $\begin{array}{l}95 \\
69 \\
\end{array}$ & $\begin{array}{l}92 \\
68 \\
\end{array}$ & 'nu zút & nu: D, I, F0 \\
\hline & $\begin{array}{l}\text { 12_2 nu } \\
\text { (vă)zut }\end{array}$ & $\begin{array}{l}49 \\
26\end{array}$ & $\begin{array}{l}80 \\
61\end{array}$ & $\begin{array}{l}97 \\
69\end{array}$ & $\begin{array}{l}95 \\
69\end{array}$ & $\begin{array}{l}92 \\
68\end{array}$ & 'nu zút & nu: D, I, F0 \\
\hline & $\begin{array}{l}\text { 14_1 n-am } \\
\text { (vă)zut }\end{array}$ & $\begin{array}{l}89 \\
71\end{array}$ & $\begin{array}{l}76 \\
66\end{array}$ & $\begin{array}{l}\mathbf{1 0 4} \\
82\end{array}$ & $\begin{array}{l}\mathbf{1 0 1} \\
80\end{array}$ & $\begin{array}{l}96 \\
72\end{array}$ & 'n-am zút & n-am: I, F0 \\
\hline & $\begin{array}{l}\text { 14_2 n-am } \\
\text { (vă)zut }\end{array}$ & $\begin{array}{l}\mathbf{8 6} \\
55\end{array}$ & $\begin{array}{l}76 \\
66\end{array}$ & $\begin{array}{l}\mathbf{1 0 4} \\
81\end{array}$ & $\begin{array}{l}101 \\
81\end{array}$ & $\begin{array}{l}97 \\
79\end{array}$ & 'n-am zút & n-am: D, I, F0 \\
\hline & $\begin{array}{l}\text { 14_3 n-am } \\
\text { (vă)zut }\end{array}$ & $\begin{array}{l}95 \\
78\end{array}$ & $\begin{array}{l}76 \\
66\end{array}$ & $\begin{array}{l}\mathbf{1 0 4} \\
82\end{array}$ & $\begin{array}{l}\mathbf{1 0 0} \\
80\end{array}$ & $\begin{array}{l}96 \\
73\end{array}$ & 'n-am zút & n-am: I, F0 \\
\hline \multirow[t]{2}{*}{ BM5 } & $\begin{array}{c}\text { twkm1 nu } \\
\text { ve }\end{array}$ & $\begin{array}{l}74 \\
98\end{array}$ & $\begin{array}{l}74 \\
78\end{array}$ & $\begin{array}{l}174 \\
\mathbf{2 0 2}\end{array}$ & $\begin{array}{l}181 \\
205\end{array}$ & $\begin{array}{l}179 \\
\mathbf{2 1 1}\end{array}$ & nù "ve & ve: I, F0 \\
\hline & $\begin{array}{ll}\text { twkm2 } & \text { nu } \\
& \text { ve }\end{array}$ & $\begin{array}{l}63 \\
94\end{array}$ & $\begin{array}{l}75 \\
80\end{array}$ & $\begin{array}{l}178 \\
175\end{array}$ & $\begin{array}{l}178 \\
169\end{array}$ & $\begin{array}{l}173 \\
167\end{array}$ & nu "ve & ve: $\mathrm{D}, \mathrm{I}$ \\
\hline
\end{tabular}




\begin{tabular}{|c|c|c|c|c|c|c|c|c|}
\hline & $\begin{array}{ll}\text { twkm3 nu } & \begin{array}{l}\text { ve } \\
\end{array}\end{array}$ & $\begin{array}{l}63 \\
\mathbf{1 0 7}\end{array}$ & $\begin{array}{l}80 \\
80\end{array}$ & $\begin{array}{l}196 \\
\mathbf{2 4 2}\end{array}$ & $\begin{array}{l}219 \\
\mathbf{2 3 7}\end{array}$ & $\begin{array}{l}228 \\
\mathbf{2 4 5}\end{array}$ & nù "ve & ve: D, F0 \\
\hline & $\begin{array}{c}\text { 12_1 nu } \\
\text { (vă)zut }\end{array}$ & $\begin{array}{l}\mathbf{8 3} \\
50\end{array}$ & $\begin{array}{l}\mathbf{8 1} \\
70\end{array}$ & $\begin{array}{l}269 \\
173\end{array}$ & $\begin{array}{l}\mathbf{2 8 1} \\
168\end{array}$ & $\begin{array}{l}\mathbf{2 6 0} \\
166\end{array}$ & "nu zút & nu: D, I, F0 \\
\hline & $\begin{array}{l}12 \_\mathrm{nu} \\
\text { (vă)zut }\end{array}$ & $\begin{array}{l}73 \\
51\end{array}$ & $\begin{array}{l}79 \\
80\end{array}$ & $\begin{array}{l}300 \\
193\end{array}$ & $\begin{array}{l}319 \\
192\end{array}$ & $\begin{array}{l}299 \\
188\end{array}$ & "nu zút & $\begin{array}{l}\text { nu: D, F0 } \\
\text { ve: I }\end{array}$ \\
\hline & $\begin{array}{c}12 \_3 \text { nu } \\
\text { (vă)zut }\end{array}$ & $\begin{array}{l}62 \\
56\end{array}$ & $\begin{array}{l}76 \\
74\end{array}$ & $\begin{array}{l}289 \\
194\end{array}$ & $\begin{array}{l}308 \\
187\end{array}$ & $\begin{array}{l}296 \\
182\end{array}$ & "nu zút & nu: I, F0 \\
\hline & $\begin{array}{l}\text { 14_1 n-am } \\
\text { (vă)zut }\end{array}$ & $\begin{array}{l}93 \\
78\end{array}$ & $\begin{array}{l}81 \\
74\end{array}$ & $\begin{array}{l}281 \\
185\end{array}$ & $\begin{array}{l}296 \\
181\end{array}$ & $\begin{array}{l}\mathbf{2 6 9} \\
171\end{array}$ & "n-am zút & n-am: I, F0 \\
\hline & $\begin{array}{l}\text { 14_2 n-am } \\
\text { (vă)zut }\end{array}$ & $\begin{array}{l}\mathbf{8 1} \\
51\end{array}$ & $\begin{array}{l}77 \\
67\end{array}$ & $\begin{array}{l}202 \\
179\end{array}$ & $\begin{array}{l}\mathbf{1 8 2} \\
170\end{array}$ & $\begin{array}{l}168 \\
168\end{array}$ & "n-am zút & n-am: D, I, F0 \\
\hline & $\begin{array}{l}\text { 14_3 n-am } \\
\text { (vă)zut }\end{array}$ & $\begin{array}{l}91 \\
53\end{array}$ & $\begin{array}{l}82 \\
68\end{array}$ & $\begin{array}{l}243 \\
158\end{array}$ & $\begin{array}{l}\mathbf{2 0 7} \\
157\end{array}$ & $\begin{array}{l}\mathbf{1 7 2} \\
156\end{array}$ & "n-am zút & n-am: D, I, F0 \\
\hline BM6 & $\begin{array}{c}\text { twkm1 nu } \\
\text { ve }\end{array}$ & $\begin{array}{l}45 \\
81\end{array}$ & $\begin{array}{l}80 \\
83\end{array}$ & $\begin{array}{l}137 \\
149\end{array}$ & $\begin{array}{l}138 \\
158\end{array}$ & $\begin{array}{l}138 \\
156\end{array}$ & "nu vé & ve: D, I, F0 \\
\hline & $\begin{array}{ll}\text { twkm2 } & \text { nu } \\
& \text { ve }\end{array}$ & $\begin{array}{l}53 \\
95\end{array}$ & $\begin{array}{l}79 \\
83\end{array}$ & $\begin{array}{l}137 \\
148\end{array}$ & $\begin{array}{l}138 \\
158\end{array}$ & $\begin{array}{l}136 \\
\mathbf{1 5 4}\end{array}$ & nu "ve & ve: D, I, F0 \\
\hline & $\begin{array}{ll}\text { twkm3 nu } & \text { ve } \\
\end{array}$ & $\begin{array}{l}37 \\
86\end{array}$ & $\begin{array}{l}80 \\
83\end{array}$ & $\begin{array}{l}137 \\
150\end{array}$ & $\begin{array}{l}138 \\
\mathbf{1 5 8}\end{array}$ & $\begin{array}{l}140 \\
\mathbf{1 5 6}\end{array}$ & nu "ve & ve: D, I, F0 \\
\hline & $\begin{array}{c}\text { 12_1 nu } \\
\text { (vă)zut }\end{array}$ & $\begin{array}{l}73 \\
72\end{array}$ & $\begin{array}{l}85 \\
82\end{array}$ & $\begin{array}{l}\mathbf{1 4 8} \\
127\end{array}$ & $\begin{array}{l}\mathbf{1 5 7} \\
134\end{array}$ & $\begin{array}{l}\mathbf{1 6 8} \\
128\end{array}$ & "nu zút & nu: I, F0 \\
\hline & $\begin{array}{c}12 \_\mathrm{nu} \\
\text { (vă)zut }\end{array}$ & $\begin{array}{l}64 \\
84\end{array}$ & $\begin{array}{l}85 \\
80\end{array}$ & $\begin{array}{l}150 \\
131\end{array}$ & $\begin{array}{l}157 \\
134\end{array}$ & $\begin{array}{l}\mathbf{1 6 6} \\
122\end{array}$ & "nu zút & nu: I, F0 \\
\hline & $\begin{array}{l}\text { 14_3 n-am } \\
\text { (vă)zut }\end{array}$ & $\begin{array}{l}107 \\
63\end{array}$ & $\begin{array}{l}82 \\
77\end{array}$ & $\begin{array}{l}\mathbf{1 3 4} \\
115\end{array}$ & $\begin{array}{l}139 \\
112\end{array}$ & $\begin{array}{l}141 \\
109\end{array}$ & "n-am zút & n-am: D, I, F0 \\
\hline Cr5 & $\begin{array}{ll}\text { twkm1 nu } \\
\text { ve }\end{array}$ & $\begin{array}{l}68 \\
61\end{array}$ & $\begin{array}{l}85 \\
83\end{array}$ & $\begin{array}{l}228 \\
229\end{array}$ & $\begin{array}{l}\mathbf{2 3 6} \\
213\end{array}$ & $\begin{array}{l}234 \\
201\end{array}$ & "nu vé & nu: I, F0 \\
\hline & $\begin{array}{ll}\text { twkm2 } & \text { nu } \\
& \text { ve }\end{array}$ & $\begin{array}{l}42 \\
74\end{array}$ & $\begin{array}{l}80 \\
86\end{array}$ & $\begin{array}{l}201 \\
194\end{array}$ & $\begin{array}{l}196 \\
201\end{array}$ & $\begin{array}{l}192 \\
209\end{array}$ & nu "ve & ve: D, I \\
\hline & $\begin{array}{ll}\text { twkm3 } & \text { nu } \\
& \text { ve }\end{array}$ & $\begin{array}{l}41 \\
\mathbf{5 7}\end{array}$ & $\begin{array}{l}78 \\
\mathbf{8 3}\end{array}$ & $\begin{array}{l}201 \\
196\end{array}$ & $\begin{array}{l}195 \\
193\end{array}$ & $\begin{array}{l}193 \\
186\end{array}$ & nu vé & ve: $\mathrm{D}, \mathrm{I}$ \\
\hline & $\begin{array}{c}12 \_1 \text { nu } \\
\text { (vă)zut }\end{array}$ & $\begin{array}{l}84 \\
52\end{array}$ & $\begin{array}{l}73 \\
61\end{array}$ & $\begin{array}{l}216 \\
216\end{array}$ & $\begin{array}{l}230 \\
211\end{array}$ & $\begin{array}{l}\mathbf{2 4 0} \\
206\end{array}$ & 'nu/"nu zút & nu: D, I, F0 \\
\hline & $\begin{array}{c}12 \_\mathrm{nu} \\
\text { (vă)zut }\end{array}$ & $\begin{array}{l}55 \\
48\end{array}$ & $\begin{array}{l}77 \\
63\end{array}$ & $\begin{array}{l}237 \\
222\end{array}$ & $\begin{array}{l}\mathbf{2 4 0} \\
224\end{array}$ & $\begin{array}{l}\mathbf{2 4 0} \\
212\end{array}$ & 'nu zút & nu: I, F0 \\
\hline & $\begin{array}{c}12 \_3 \text { nu } \\
\text { (vă)zut }\end{array}$ & $\begin{array}{l}48 \\
31\end{array}$ & $\begin{array}{l}72 \\
55\end{array}$ & $\begin{array}{l}211 \\
193\end{array}$ & $\begin{array}{l}\mathbf{2 1 3} \\
193\end{array}$ & $\begin{array}{l}211 \\
194\end{array}$ & 'nu zút & nu: D, I, F0 \\
\hline & $\begin{array}{c}12 \text { _5 nu } \\
\text { (vă)zut }\end{array}$ & $\begin{array}{l}40 \\
56\end{array}$ & $\begin{array}{l}72 \\
64\end{array}$ & $\begin{array}{l}213 \\
199\end{array}$ & $\begin{array}{l}216 \\
202\end{array}$ & $\begin{array}{l}217 \\
203\end{array}$ & 'nu zút & $\begin{array}{l}\text { nu: I } \\
\text { zut: D }\end{array}$ \\
\hline & $\begin{array}{c}12 \_6 \text { nu } \\
\text { (vă)zut }\end{array}$ & $\begin{array}{l}47 \\
54\end{array}$ & $\begin{array}{l}76 \\
65\end{array}$ & $\begin{array}{l}\mathbf{2 1 4} \\
196\end{array}$ & $\begin{array}{l}\mathbf{2 1 5} \\
194\end{array}$ & $\begin{array}{l}\mathbf{2 1 8} \\
191\end{array}$ & 'nu zút & $\begin{array}{l}\text { nu: I, F0 } \\
\text { vc }\end{array}$ \\
\hline
\end{tabular}




\begin{tabular}{|c|c|c|c|c|c|c|c|c|}
\hline \multirow[t]{17}{*}{ Cr6 } & $\begin{array}{ll}\text { twkm1 nu } & \text { ve }\end{array}$ & $\begin{array}{l}77 \\
66\end{array}$ & $\begin{array}{l}\mathbf{8 3} \\
82\end{array}$ & $\begin{array}{l}115 \\
129\end{array}$ & $\begin{array}{l}116 \\
\mathbf{1 3 1}\end{array}$ & $\begin{array}{l}116 \\
123\end{array}$ & nù vé & $\begin{array}{l}\text { nu: I } \\
\text { ve: F0 (2) }\end{array}$ \\
\hline & twkm2 nu & 66 & 82 & 115 & 117 & 116 & \multirow[t]{2}{*}{ nu vé } & \multirow[t]{2}{*}{ ve: I } \\
\hline & ve & 68 & 83 & 122 & 123 & 117 & & \\
\hline & twkm3 nu & 67 & 79 & 106 & 107 & 108 & \multirow[t]{2}{*}{ nu vé } & \multirow[t]{2}{*}{ ve: I, F0 } \\
\hline & ve & 66 & 81 & 136 & 134 & 127 & & \\
\hline & 12_1 nu & 91 & 77 & 133 & 132 & 143 & \multirow[t]{2}{*}{ 'nu zút } & \\
\hline & (vă)zut & 84 & 77 & 141 & 141 & 137 & & \\
\hline & $122 \mathrm{nu}$ & 64 & 77 & 141 & 144 & 138 & \multirow[t]{2}{*}{ "nu zút } & \multirow[t]{2}{*}{ nu: I, F0 } \\
\hline & (vă)zut & 44 & 75 & 118 & 119 & 118 & & \\
\hline & $123 \mathrm{nu}$ & 72 & 75 & 158 & 166 & 159 & \multirow[t]{2}{*}{ "nu zút } & \multirow[t]{2}{*}{ nu: I, F0 } \\
\hline & (vă)zut & 67 & 67 & 103 & 100 & 98 & & \\
\hline & 141 n-am & 114 & 78 & 149 & 166 & 157 & \multirow{2}{*}{ "n-am zút } & \multirow{2}{*}{ n-am: D, I, F0 } \\
\hline & (vă)zut & 74 & 66 & 101 & 98 & 96 & & \\
\hline & 142 n-am & 94 & 82 & 170 & 172 & 154 & \multirow[t]{2}{*}{ "n-am zút } & \multirow[t]{2}{*}{ n-am: I, F0 } \\
\hline & (vă)zut & 77 & 70 & 104 & 99 & 98 & & \\
\hline & $14 \_3$ n-am & 96 & 81 & 162 & 156 & 119 & \multirow[t]{2}{*}{ "n-am zút } & \multirow[t]{2}{*}{ n-am: I, F0 } \\
\hline & (vă)zut & 74 & 71 & 96 & 91 & 95 & & \\
\hline \multirow[t]{16}{*}{ Cs5 } & twkml nu & 82 & 69 & 174 & 170 & 166 & \multirow[t]{2}{*}{ nu vé } & \multirow[t]{2}{*}{ ve: I } \\
\hline & ve & 94 & 70 & 175 & 168 & 166 & & \\
\hline & twkm2 nu & 113 & 74 & 168 & 169 & 162 & \multirow[t]{2}{*}{ nù vé } & \multirow[t]{2}{*}{ nu: I } \\
\hline & ve & 115 & 71 & 178 & 159 & 154 & & \\
\hline & twkm3 nu & 142 & 69 & 184 & 184 & 168 & \multirow[t]{3}{*}{ nú vé } & \\
\hline & & 101 & 70 & 175 & 168 & 165 & & $(2)$ \\
\hline & & & & & & & & \\
\hline & $12 \_1 \mathrm{nu}$ & 64 & 81 & 277 & 264 & 233 & "nu zút & nu: I, F0 \\
\hline & (vă)zut & 61 & 70 & 168 & 160 & 177 & & zut: I \\
\hline & $141 \mathrm{n}$-am & 143 & 72 & 177 & 193 & 212 & "n-am zút & n-am: D, F0 \\
\hline & (vă)zut & 103 & 74 & 210 & 212 & 211 & & nivel maxim \\
\hline & & & & & & & & pe $m$; ve: I, F0 \\
\hline & 14_2n-am & 125 & 77 & 225 & 256 & 255 & "n-am zút & n-am: D; I, F0 \\
\hline & (vă)zut & 74 & 75 & 221 & 227 & 217 & & \\
\hline & 14_3 n-am & 112 & 79 & 218 & 231 & 235 & "n-am zút & n-am: I, F0 \\
\hline & (vă)zut & 97 & 67 & 176 & 168 & 172 & & \\
\hline Cs6 & twkm1 nu & 113 & 81 & 138 & 150 & 130 & "nu vé & nu: I, F0 \\
\hline & ve & 120 & 80 & 117 & 120 & 131 & & \\
\hline & twkm2 nu & 147 & 78 & 123 & 142 & 139 & "nu vé & nu: D, F0(2) \\
\hline & ve & 115 & 78 & 118 & 128 & 134 & & \\
\hline & twkm3 nu & 124 & 82 & 140 & 164 & 187 & "nu vé & nu: I, F0 \\
\hline & ve & 121 & 79 & 115 & 119 & 132 & & \\
\hline & $12 \_1 \mathrm{nu}$ & 55 & 84 & 163 & 150 & 136 & "nu zút & nu: I, F0 \\
\hline & (vă)zut & 65 & 64 & 86 & 88 & 86 & & \\
\hline
\end{tabular}




\begin{tabular}{|c|c|c|c|c|c|c|c|c|}
\hline & $\begin{array}{c}12 \_ \text {nu } \\
\text { (vă)zut }\end{array}$ & $\begin{array}{l}59 \\
65\end{array}$ & $\begin{array}{l}81 \\
67 \\
\end{array}$ & $\begin{array}{l}230 \\
93\end{array}$ & $\begin{array}{l}225 \\
92 \\
\end{array}$ & $\begin{array}{l}199 \\
91 \\
\end{array}$ & "nu zút & nu: I, F0 \\
\hline & $\begin{array}{l}\text { 14_1no-am } \\
\text { (vă)zut }\end{array}$ & $\begin{array}{l}109 \\
62\end{array}$ & $\begin{array}{l}81 \\
68\end{array}$ & $\begin{array}{l}146 \\
95\end{array}$ & $\begin{array}{l}147 \\
93\end{array}$ & $\begin{array}{l}133 \\
98\end{array}$ & "no-am zút & no-am: D, I, F0 \\
\hline \multirow{8}{*}{ Iș5 } & $\begin{array}{c}\text { twkm1 nu } \\
\text { ve }\end{array}$ & $\begin{array}{l}72 \\
97\end{array}$ & $\begin{array}{l}74 \\
75\end{array}$ & $\begin{array}{l}255 \\
244\end{array}$ & $\begin{array}{l}\mathbf{2 5 5} \\
239\end{array}$ & $\begin{array}{l}243 \\
244\end{array}$ & nù vé & $\begin{array}{l}\text { nu: F0(2) } \\
\text { ve: I }\end{array}$ \\
\hline & $\begin{array}{ll}\text { twkm2 nu } & \text { ve } \\
\end{array}$ & $\begin{array}{l}78 \\
88\end{array}$ & $\begin{array}{l}74 \\
75\end{array}$ & $\begin{array}{l}231 \\
230\end{array}$ & $\begin{array}{l}235 \\
218\end{array}$ & $\begin{array}{l}232 \\
219\end{array}$ & nù vé & $\begin{array}{l}\text { nu: F0(2) } \\
\text { ve: I }\end{array}$ \\
\hline & $\begin{array}{ll}\text { twkm3 nu } & \text { ve }\end{array}$ & $\begin{array}{l}91 \\
92\end{array}$ & $\begin{array}{l}73 \\
77\end{array}$ & $\begin{array}{l}223 \\
232\end{array}$ & $\begin{array}{l}227 \\
220\end{array}$ & $\begin{array}{l}219 \\
224\end{array}$ & nu vé & ve: I \\
\hline & $\begin{array}{c}12 \_1 \text { nu } \\
\text { (vă)zut }\end{array}$ & $\begin{array}{l}57 \\
49\end{array}$ & $\begin{array}{l}70 \\
67\end{array}$ & $\begin{array}{l}289 \\
182\end{array}$ & $\begin{array}{l}307 \\
180\end{array}$ & $\begin{array}{l}304 \\
175\end{array}$ & "nu zút & nu: I, F0 \\
\hline & $\begin{array}{l}12 \_\mathrm{nu} \\
\text { (vă)zut }\end{array}$ & $\begin{array}{l}68 \\
62\end{array}$ & $\begin{array}{l}72 \\
63\end{array}$ & $\begin{array}{l}237 \\
181\end{array}$ & $\begin{array}{l}269 \\
174\end{array}$ & $\begin{array}{l}289 \\
169\end{array}$ & "nu zút & nu: I, F0 \\
\hline & $\begin{array}{c}12 \_3 \mathrm{nu} \\
\text { (vă)zut }\end{array}$ & $\begin{array}{l}69 \\
50\end{array}$ & $\begin{array}{l}71 \\
65\end{array}$ & $\begin{array}{l}\mathbf{2 5 1} \\
172\end{array}$ & $\begin{array}{l}287 \\
168\end{array}$ & $\begin{array}{l}299 \\
164\end{array}$ & "nu zút & nu: D, I, F0 \\
\hline & $\begin{array}{l}\text { 14_1 n-am } \\
\text { (vă)zut }\end{array}$ & $\begin{array}{l}81 \\
48\end{array}$ & $\begin{array}{l}73 \\
70\end{array}$ & $\begin{array}{l}269 \\
218\end{array}$ & $\begin{array}{l}\mathbf{2 8 7} \\
217\end{array}$ & $\begin{array}{l}306 \\
215\end{array}$ & "n-am zút & n-am: D, I, F0 \\
\hline & $\begin{array}{l}142 \text { n-am } \\
\text { (vă)zut }\end{array}$ & $\begin{array}{l}95 \\
58 \\
\end{array}$ & $\begin{array}{l}74 \\
65 \\
\end{array}$ & $\begin{array}{l}259 \\
194 \\
\end{array}$ & $\begin{array}{l}278 \\
185 \\
\end{array}$ & $\begin{array}{l}294 \\
181 \\
\end{array}$ & "n-am zút & n-am: D, I, F0 \\
\hline \multirow{9}{*}{ Iș6 } & $\begin{array}{ll}\text { twkm1 nu } \\
\text { ve }\end{array}$ & $\begin{array}{l}74 \\
86\end{array}$ & $\begin{array}{l}69 \\
74\end{array}$ & $\begin{array}{l}118 \\
111\end{array}$ & $\begin{array}{l}114 \\
106\end{array}$ & $\begin{array}{l}107 \\
101\end{array}$ & nu vé & ve: I \\
\hline & $\begin{array}{ll}\text { twkm2 nu } & \text { ve } \\
& \end{array}$ & $\begin{array}{l}62 \\
93\end{array}$ & $\begin{array}{l}71 \\
76\end{array}$ & $\begin{array}{l}120 \\
112\end{array}$ & $\begin{array}{l}120 \\
110\end{array}$ & $\begin{array}{l}115 \\
103\end{array}$ & nu vé & ve: I \\
\hline & $\begin{array}{ll}\text { twkm3 } & \text { nu } \\
& \text { ve }\end{array}$ & $\begin{array}{l}91 \\
88\end{array}$ & $\begin{array}{l}73 \\
77\end{array}$ & $\begin{array}{l}127 \\
116\end{array}$ & $\begin{array}{l}124 \\
113\end{array}$ & $\begin{array}{l}115 \\
109\end{array}$ & nu vé & ve: I \\
\hline & $\begin{array}{c}12 \_1 \text { nu } \\
\text { (vă)zut }\end{array}$ & $\begin{array}{l}53 \\
104 \\
\end{array}$ & $\begin{array}{l}76 \\
74\end{array}$ & $\begin{array}{l}\mathbf{1 7 2} \\
112\end{array}$ & $\begin{array}{l}\mathbf{1 7 1} \\
108\end{array}$ & $\begin{array}{l}\mathbf{1 6 7} \\
106\end{array}$ & "nu zút & $\begin{array}{l}\text { nu: I, F0 } \\
\text { ve: D }\end{array}$ \\
\hline & $\begin{array}{c}12 \_ \text {nu } \\
\text { (vă)zut }\end{array}$ & $\begin{array}{l}91 \\
99 \\
\end{array}$ & $\begin{array}{l}81 \\
74\end{array}$ & $\begin{array}{l}\mathbf{1 5 6} \\
105\end{array}$ & $\begin{array}{l}\mathbf{1 5 2} \\
101\end{array}$ & $\begin{array}{l}144 \\
104\end{array}$ & "nu zút & ve: I, F0 \\
\hline & $\begin{array}{l}12 \_3 \mathrm{nu} \\
\text { (vă)zut }\end{array}$ & $\begin{array}{l}94 \\
80\end{array}$ & $\begin{array}{l}74 \\
71\end{array}$ & $\begin{array}{l}125 \\
113\end{array}$ & $\begin{array}{l}124 \\
114\end{array}$ & $\begin{array}{l}123 \\
112\end{array}$ & "nu zút & nu: I \\
\hline & $\begin{array}{l}\text { 14_1 n-am } \\
\text { (vă)zut }\end{array}$ & $\begin{array}{l}92 \\
77\end{array}$ & $\begin{array}{l}79 \\
71\end{array}$ & $\begin{array}{l}\mathbf{1 4 5} \\
115\end{array}$ & $\begin{array}{l}154 \\
106\end{array}$ & $\begin{array}{l}157 \\
113\end{array}$ & "n-am zút & n-am: I, F0 \\
\hline & $\begin{array}{l}\text { 14_2 n-am } \\
\text { (vă)zut }\end{array}$ & $\begin{array}{l}133 \\
77\end{array}$ & $\begin{array}{l}79 \\
72\end{array}$ & $\begin{array}{l}\mathbf{1 6 1} \\
114\end{array}$ & $\begin{array}{l}161 \\
109\end{array}$ & $\begin{array}{l}149 \\
103\end{array}$ & "n-am zút & n-am: D, I, F0 \\
\hline & $\begin{array}{l}143 \text { n-am } \\
\text { (vă)zut }\end{array}$ & $\begin{array}{l}132 \\
77 \\
\end{array}$ & $\begin{array}{l}81 \\
72 \\
\end{array}$ & $\begin{array}{l}\mathbf{1 8 6} \\
107 \\
\end{array}$ & $\begin{array}{l}\mathbf{1 7 1} \\
100 \\
\end{array}$ & $\begin{array}{l}146 \\
108 \\
\end{array}$ & "n-am zút & n-am: D, I, F0 \\
\hline \multirow[t]{2}{*}{ T5 } & $\begin{array}{r}\text { twkm1 nu } \\
\text { ve }\end{array}$ & $\begin{array}{l}54 \\
77 \\
\end{array}$ & $\begin{array}{l}71 \\
80\end{array}$ & $\begin{array}{l}189 \\
208\end{array}$ & $\begin{array}{l}189 \\
\mathbf{2 1 8}\end{array}$ & $\begin{array}{l}190 \\
\mathbf{2 2 1} \\
\end{array}$ & nu "ve & ve: I, F0 \\
\hline & $\begin{array}{ll}\text { twkm2 } & \text { nu } \\
& \text { ve }\end{array}$ & $\begin{array}{l}49 \\
64\end{array}$ & $\begin{array}{l}68 \\
75\end{array}$ & $\begin{array}{l}180 \\
197\end{array}$ & $\begin{array}{l}178 \\
204\end{array}$ & $\begin{array}{l}177 \\
206\end{array}$ & nu "ve & ve: I, F0 \\
\hline
\end{tabular}




\begin{tabular}{|c|c|c|c|c|c|c|c|c|}
\hline & $\begin{array}{ll}\text { twkm3 nu } & \text { ve }\end{array}$ & $\begin{array}{l}61 \\
73\end{array}$ & $\begin{array}{l}73 \\
80\end{array}$ & $\begin{array}{l}176 \\
190\end{array}$ & $\begin{array}{l}173 \\
200\end{array}$ & $\begin{array}{l}174 \\
\mathbf{2 0 3}\end{array}$ & nu "ve & ve: I, F0 \\
\hline & $\begin{array}{c}12 \_1 \mathrm{nu} \\
\text { (vă)zut }\end{array}$ & $\begin{array}{l}66 \\
45\end{array}$ & $\begin{array}{l}71 \\
68\end{array}$ & $\begin{array}{l}233 \\
197\end{array}$ & $\begin{array}{l}239 \\
201\end{array}$ & $\begin{array}{l}239 \\
195\end{array}$ & 'nu/"nu zút & nu: D, I, F0 \\
\hline & $\begin{array}{c}12 \text { _2 nu } \\
\text { (vă)zut }\end{array}$ & $\begin{array}{l}67 \\
71\end{array}$ & $\begin{array}{l}76 \\
74\end{array}$ & $\begin{array}{l}\mathbf{2 4 6} \\
211\end{array}$ & $\begin{array}{l}\mathbf{2 5 5} \\
218\end{array}$ & $\begin{array}{l}\mathbf{2 6 0} \\
215\end{array}$ & "nu zút & nu: I, F0 \\
\hline & $\begin{array}{c}12 \_3 \mathrm{nu} \\
\text { (vă)zut }\end{array}$ & $\begin{array}{l}53 \\
64\end{array}$ & $\begin{array}{l}78 \\
79\end{array}$ & $\begin{array}{l}236 \\
207\end{array}$ & $\begin{array}{l}239 \\
216\end{array}$ & $\begin{array}{l}\mathbf{2 4 2} \\
219\end{array}$ & 'nu zút & $\begin{array}{l}\text { nu: F0 } \\
\text { zut: I }\end{array}$ \\
\hline & $\begin{array}{l}\text { 14_1 n-am } \\
\text { (vă)zut }\end{array}$ & $\begin{array}{l}89 \\
65\end{array}$ & $\begin{array}{l}75 \\
71\end{array}$ & $\begin{array}{l}278 \\
162\end{array}$ & $\begin{array}{l}271 \\
160\end{array}$ & $\begin{array}{l}\mathbf{2 4 4} \\
157\end{array}$ & "n-am zút & $\begin{array}{l}\text { n-am: D, I, } \\
\text { F0 }\end{array}$ \\
\hline & $\begin{array}{l}142 \text { n-am } \\
\text { (vă)zut }\end{array}$ & $\begin{array}{l}99 \\
75\end{array}$ & $\begin{array}{l}82 \\
76\end{array}$ & $\begin{array}{l}264 \\
169\end{array}$ & $\begin{array}{l}269 \\
171\end{array}$ & $\begin{array}{l}261 \\
166\end{array}$ & "n-am zút & n-am: D, I, F0 \\
\hline & $\begin{array}{l}\text { 14_3 n-am } \\
\text { (vă)zut }\end{array}$ & $\begin{array}{l}84 \\
82\end{array}$ & $\begin{array}{l}80 \\
80\end{array}$ & $\begin{array}{l}228 \\
237\end{array}$ & $\begin{array}{l}237 \\
236\end{array}$ & $\begin{array}{l}\mathbf{2 4 8} \\
222\end{array}$ & "n-am zút & $\begin{array}{l}\text { n-am:F0(3), } \\
\text { ni-vel } \\
\text { maxim pe } m\end{array}$ \\
\hline T6 & $\begin{array}{ll}\text { twkm1 nu } & \text { ve }\end{array}$ & $\begin{array}{l}73 \\
85\end{array}$ & $\begin{array}{l}68 \\
78\end{array}$ & $\begin{array}{l}93 \\
102\end{array}$ & $\begin{array}{l}93 \\
102\end{array}$ & $\begin{array}{l}90 \\
100\end{array}$ & nu "ve & ve: I \\
\hline & $\begin{array}{ll}\text { twkm2 nu } & \text { ve }\end{array}$ & $\begin{array}{l}66 \\
73\end{array}$ & $\begin{array}{l}71 \\
77\end{array}$ & $\begin{array}{l}95 \\
107\end{array}$ & $\begin{array}{l}93 \\
107\end{array}$ & $\begin{array}{l}92 \\
107\end{array}$ & nu "ve & ve: I, F0 (3) \\
\hline & $\begin{array}{ll}\text { twkm3 nu } & \text { ve } \\
& \end{array}$ & $\begin{array}{l}75 \\
86\end{array}$ & $\begin{array}{l}71 \\
81 \\
\end{array}$ & $\begin{array}{l}94 \\
105\end{array}$ & $\begin{array}{l}94 \\
106\end{array}$ & $\begin{array}{l}94 \\
107\end{array}$ & nu "ve & ve: I \\
\hline & $\begin{array}{c}12 \_1 \text { nu } \\
\text { (vă)zut }\end{array}$ & $\begin{array}{l}67 \\
50\end{array}$ & $\begin{array}{l}73 \\
68 \\
\end{array}$ & $\begin{array}{l}\mathbf{1 7 0} \\
107\end{array}$ & $\begin{array}{l}\mathbf{1 8 5} \\
108\end{array}$ & $\begin{array}{l}195 \\
93\end{array}$ & "nu zút & nu: D, I, F0 \\
\hline & $\begin{array}{c}12 \_\mathrm{nu} \\
\text { (vă)zut }\end{array}$ & $\begin{array}{l}68 \\
77 \\
\end{array}$ & $\begin{array}{l}79 \\
77 \\
\end{array}$ & $\begin{array}{l}149 \\
111 \\
\end{array}$ & $\begin{array}{l}162 \\
108 \\
\end{array}$ & $\begin{array}{l}168 \\
97 \\
\end{array}$ & "nu zút & nu: I, F0 \\
\hline & $\begin{array}{c}12 \_3 \mathrm{nu} \\
\text { (vă)zut }\end{array}$ & $\begin{array}{l}60 \\
56 \\
\end{array}$ & $\begin{array}{l}76 \\
69 \\
\end{array}$ & $\begin{array}{l}153 \\
107 \\
\end{array}$ & $\begin{array}{l}163 \\
104 \\
\end{array}$ & $\begin{array}{l}170 \\
92 \\
\end{array}$ & "nu zút & nu: I, F0 \\
\hline & $\begin{array}{l}\text { 14_1 n-am } \\
\text { (vă)zut }\end{array}$ & $\begin{array}{l}91 \\
58 \\
\end{array}$ & $\begin{array}{l}83 \\
76 \\
\end{array}$ & $\begin{array}{l}\mathbf{1 7 1} \\
115 \\
\end{array}$ & $\begin{array}{l}\mathbf{1 8 4} \\
114 \\
\end{array}$ & $\begin{array}{l}\mathbf{1 8 1} \\
106 \\
\end{array}$ & "n-am zút & n-am: D, I, F0 \\
\hline & $\begin{array}{l}14 \_2 \text { n-am } \\
\text { (vă)zut }\end{array}$ & $\begin{array}{l}79 \\
50\end{array}$ & $\begin{array}{l}83 \\
77\end{array}$ & $\begin{array}{l}\mathbf{1 4 7} \\
111\end{array}$ & $\begin{array}{l}152 \\
109\end{array}$ & $\begin{array}{l}\mathbf{1 5 0} \\
106\end{array}$ & "n-am zút & n-am: D, I, F0 \\
\hline & $\begin{array}{l}1433 \text { n-am } \\
\text { (vă)zut }\end{array}$ & $\begin{array}{l}87 \\
70\end{array}$ & $\begin{array}{l}81 \\
75 \\
\end{array}$ & $\begin{array}{l}\mathbf{1 7 5} \\
114\end{array}$ & $\begin{array}{l}190 \\
111\end{array}$ & $\begin{array}{l}\mathbf{1 8 5} \\
102\end{array}$ & "n-am zút & n-am: I, F0 \\
\hline
\end{tabular}

ANEXĂ: TABEL 2

\begin{tabular}{|c|c|c|c|c|c|c|c|c|}
\hline $\begin{array}{l}\text { Infor- } \\
\text { mator }\end{array}$ & Enunț & D & I & F0 (F1, & F2, & F3) & $\begin{array}{l}\text { Proeminență } \\
\text { auditivă }\end{array}$ & $\begin{array}{l}\text { Indici } \\
\text { acustici }\end{array}$ \\
\hline \multirow[t]{2}{*}{ B5 } & $\begin{array}{c}\text { twkm1 nu } \\
\text { ve }\end{array}$ & $\begin{array}{l}60 \\
70\end{array}$ & $\begin{array}{l}69 \\
75\end{array}$ & $\begin{array}{l}192 \\
191\end{array}$ & $\begin{array}{l}187 \\
190\end{array}$ & $\begin{array}{l}184 \\
184\end{array}$ & nu vé & ve: I \\
\hline & $\begin{array}{ll}\text { twkm2 nu } & \text { ve }\end{array}$ & $\begin{array}{l}62 \\
74\end{array}$ & $\begin{array}{l}75 \\
77\end{array}$ & $\begin{array}{l}207 \\
202\end{array}$ & $\begin{array}{l}201 \\
198\end{array}$ & $\begin{array}{l}194 \\
193\end{array}$ & nu vé & ve: I \\
\hline
\end{tabular}




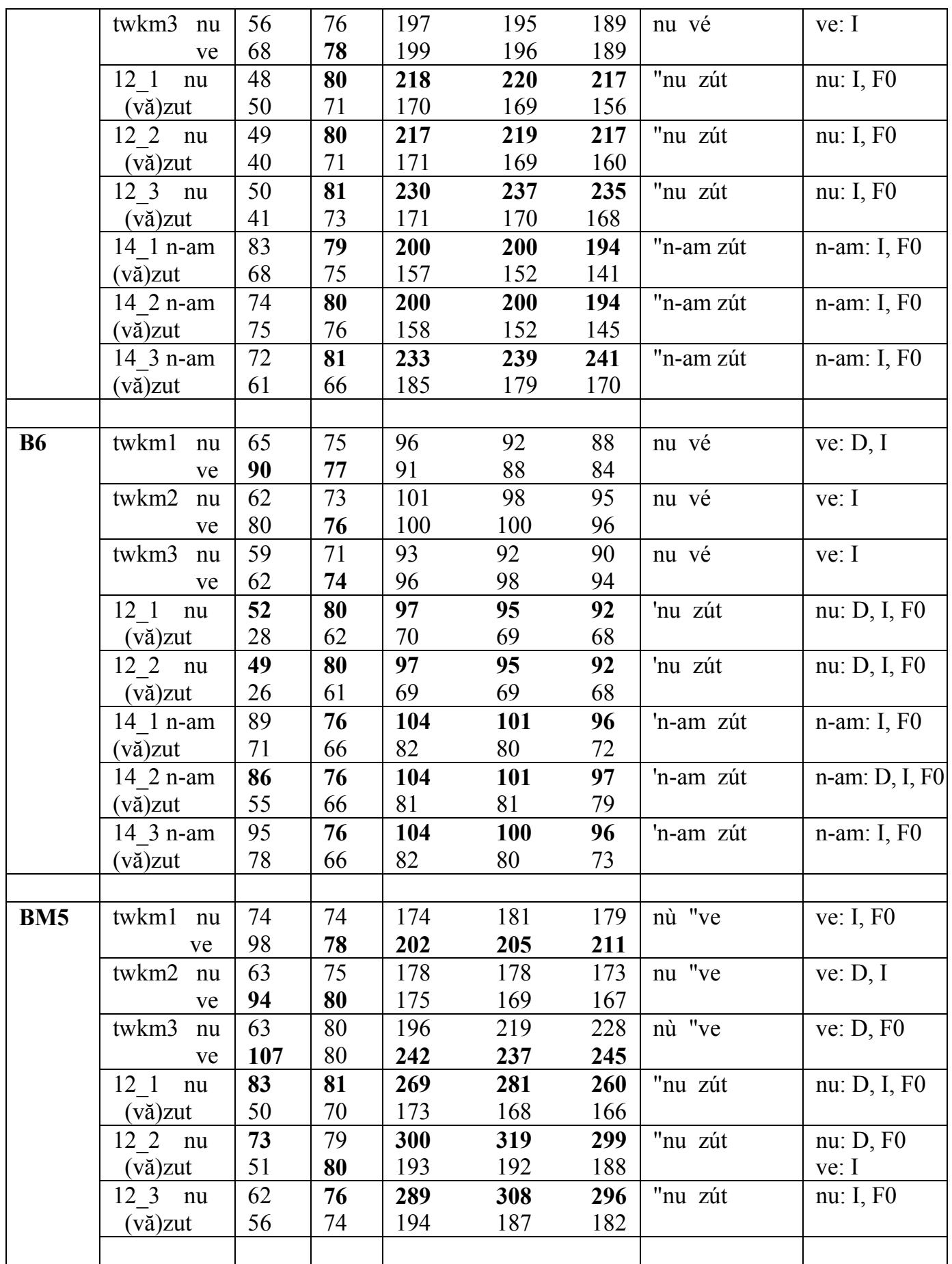




\begin{tabular}{|c|c|c|c|c|c|c|c|c|}
\hline & $\begin{array}{l}14 \_1 \text { n-am } \\
\text { (vă)zut }\end{array}$ & $\begin{array}{l}93 \\
78 \\
\end{array}$ & $\begin{array}{l}81 \\
74\end{array}$ & $\begin{array}{l}\mathbf{2 8 1} \\
185 \\
\end{array}$ & $\begin{array}{l}296 \\
181 \\
\end{array}$ & $\begin{array}{l}\mathbf{2 6 9} \\
171 \\
\end{array}$ & "n-am zút & n-am: I, F0 \\
\hline & 14_2n-am & 81 & 77 & 202 & 182 & 168 & "n-am zút & n-am: D, I, F0 \\
\hline & (vă)zut & 51 & 67 & 179 & 170 & 168 & & \\
\hline & $\begin{array}{l}143 \text { n-am } \\
\text { (vă)zut }\end{array}$ & $\begin{array}{l}91 \\
53\end{array}$ & $\begin{array}{l}82 \\
68\end{array}$ & $\begin{array}{l}243 \\
158\end{array}$ & $\begin{array}{l}\mathbf{2 0 7} \\
157\end{array}$ & $\begin{array}{l}\mathbf{1 7 2} \\
156\end{array}$ & "n-am zút & n-am: D, I, F0 \\
\hline BM6 & twkm1 nu & 45 & 80 & 137 & 138 & 138 & "nu vé & ve: $\mathrm{D}, \mathrm{I}, \mathrm{F} 0$ \\
\hline & ve & 81 & 83 & 149 & 158 & 156 & & \\
\hline & twkm2 nu & 53 & 79 & 137 & 138 & 136 & nu "ve & ve: $\mathrm{D}, \mathrm{I}, \mathrm{F} 0$ \\
\hline & ve & 95 & 83 & 148 & 158 & 154 & & \\
\hline & twkm3 nu & 37 & 80 & 137 & 138 & 140 & nu "ve & ve: D, I, F0 \\
\hline & ve & 86 & 83 & 150 & 158 & 156 & & \\
\hline & 12_1 nu & 73 & 85 & 148 & 157 & 168 & "nu zút & nu: I, F0 \\
\hline & (vă)zut & 72 & 82 & 127 & 134 & 128 & & \\
\hline & $12 \_\mathrm{nu}$ & 64 & 85 & 150 & 157 & 166 & "nu zút & nu: I, F0 \\
\hline & (vă)zut & 84 & 80 & 131 & 134 & 122 & & \\
\hline & 14_3 n-am & 107 & 82 & 134 & 139 & 141 & "n-am zút & n-am: D, I, F0 \\
\hline & (vă)zut & 63 & 77 & 115 & 112 & 109 & & \\
\hline Cr5 & twkm1 nu & 68 & 85 & 228 & 236 & 234 & "nu vé & nu: I, F0 \\
\hline & ve & 61 & 83 & 229 & 213 & 201 & & \\
\hline & twkm2 nu & 42 & 80 & 201 & 196 & 192 & nu "ve & ve: D, I \\
\hline & ve & 74 & 86 & 194 & 201 & 209 & & \\
\hline & twkm3 nu & 41 & 78 & 201 & 195 & 193 & nu vé & ve: D, I \\
\hline & ve & 57 & 83 & 196 & 193 & 186 & & \\
\hline & 12_1 nu & 84 & 73 & 216 & 230 & 240 & 'nu /"nu zút & nu: D, I, F0 \\
\hline & (vă)zut & 52 & 61 & 216 & 211 & 206 & & \\
\hline & 12_2 nu & 55 & 77 & 237 & 240 & 240 & 'nu zút & nu: I, F0 \\
\hline & (vă)zut & 48 & 63 & 222 & 224 & 212 & & \\
\hline & $123 \mathrm{nu}$ & 48 & 72 & 211 & 213 & 211 & 'nu zút & nu: D, I, F0 \\
\hline & (vă)zut & 31 & 55 & 193 & 193 & 194 & & \\
\hline & $12 \_5 \mathrm{nu}$ & 40 & 72 & 213 & 216 & 217 & 'nu zút & nu: I \\
\hline & (vă)zut & 56 & 64 & 199 & 202 & 203 & & zut: D \\
\hline & $126 \mathrm{nu}$ & 47 & 76 & 214 & 215 & 218 & 'nu zút & nu: I, F0 \\
\hline & (vă)zut & 54 & 65 & 196 & 194 & 191 & & $\mathrm{VC}$ \\
\hline Cr6 & twkm1 nu & 77 & 83 & 115 & 116 & 116 & nù vé & nu: I \\
\hline & ve & 66 & 82 & 129 & 131 & 123 & & ve: F0 (2) \\
\hline & twkm2 nu & 66 & 82 & 115 & 117 & 116 & nu vé & ve: I \\
\hline & ve & 68 & 83 & 122 & 123 & 117 & & \\
\hline & twkm3 nu & 67 & 79 & 106 & 107 & 108 & nu vé & ve: I, F0 \\
\hline & & 66 & 81 & 136 & 134 & 127 & & \\
\hline & 12_1 nu & 91 & 77 & 133 & 132 & 143 & 'nu zút & \\
\hline & (vă)zut & 84 & 77 & 141 & 141 & 137 & & \\
\hline
\end{tabular}




\begin{tabular}{|c|c|c|c|c|c|c|c|c|}
\hline & $\begin{array}{c}12 \_ \text {nu } \\
\text { (vă)zut }\end{array}$ & $\begin{array}{l}64 \\
44 \\
\end{array}$ & $\begin{array}{l}77 \\
75 \\
\end{array}$ & $\begin{array}{l}\mathbf{1 4 1} \\
118 \\
\end{array}$ & $\begin{array}{l}144 \\
119 \\
\end{array}$ & $\begin{array}{l}138 \\
118 \\
\end{array}$ & "nu zút & nu: I, F0 \\
\hline & $\begin{array}{c}12 \_3 \text { nu } \\
\text { (vă)zut }\end{array}$ & $\begin{array}{l}72 \\
67\end{array}$ & $\begin{array}{l}75 \\
67\end{array}$ & $\begin{array}{l}158 \\
103\end{array}$ & $\begin{array}{l}\mathbf{1 6 6} \\
100\end{array}$ & $\begin{array}{l}\mathbf{1 5 9} \\
98\end{array}$ & "nu zút & nu: I, F0 \\
\hline & $\begin{array}{l}\text { 14_1 n-am } \\
\text { (vă)zut }\end{array}$ & $\begin{array}{l}114 \\
74\end{array}$ & $\begin{array}{l}78 \\
66\end{array}$ & $\begin{array}{l}149 \\
101\end{array}$ & $\begin{array}{l}166 \\
98\end{array}$ & $\begin{array}{l}\mathbf{1 5 7} \\
96\end{array}$ & "n-am zút & n-am: D, I, F0 \\
\hline & $\begin{array}{l}\text { 14_2 n-am } \\
\text { (vă)zut }\end{array}$ & $\begin{array}{l}94 \\
77 \\
\end{array}$ & $\begin{array}{l}82 \\
70\end{array}$ & $\begin{array}{l}\mathbf{1 7 0} \\
104\end{array}$ & $\begin{array}{l}172 \\
99\end{array}$ & $\begin{array}{l}\mathbf{1 5 4} \\
98\end{array}$ & "n-am zút & n-am: I, F0 \\
\hline & $\begin{array}{l}\text { 14_3 n-am } \\
\text { (vă)zut }\end{array}$ & $\begin{array}{l}96 \\
74\end{array}$ & $\begin{array}{l}\mathbf{8 1} \\
71\end{array}$ & $\begin{array}{l}\mathbf{1 6 2} \\
96\end{array}$ & $\begin{array}{l}\mathbf{1 5 6} \\
91\end{array}$ & $\begin{array}{l}119 \\
95\end{array}$ & "n-am zút & n-am: I, F0 \\
\hline \multirow[t]{7}{*}{ Cs5 } & $\begin{array}{c}\text { twkm1 nu } \\
\text { ve }\end{array}$ & $\begin{array}{l}82 \\
94\end{array}$ & $\begin{array}{l}69 \\
70\end{array}$ & $\begin{array}{l}174 \\
175\end{array}$ & $\begin{array}{l}170 \\
168\end{array}$ & $\begin{array}{l}166 \\
166\end{array}$ & nu vé & ve: I \\
\hline & $\begin{array}{ll}\text { twkm2 nu } & \begin{array}{l}\text { ve } \\
\end{array} \\
\end{array}$ & $\begin{array}{l}113 \\
115 \\
\end{array}$ & $\begin{array}{l}74 \\
71 \\
\end{array}$ & $\begin{array}{l}168 \\
178 \\
\end{array}$ & $\begin{array}{l}169 \\
159 \\
\end{array}$ & $\begin{array}{l}162 \\
154 \\
\end{array}$ & nù vé & nu: I \\
\hline & $\begin{array}{ll}\text { twkm3 nu } \\
\text { ve }\end{array}$ & $\begin{array}{l}142 \\
101\end{array}$ & $\begin{array}{l}69 \\
70\end{array}$ & $\begin{array}{l}184 \\
175\end{array}$ & $\begin{array}{l}\mathbf{1 8 4} \\
168\end{array}$ & $\begin{array}{l}168 \\
165\end{array}$ & nú vé & $\begin{array}{ll}\text { nu: } \mathrm{D}, \mathrm{F} 0 \\
(2) & \\
\text { ve: I } & \end{array}$ \\
\hline & $\begin{array}{c}12 \_1 \quad \text { nu } \\
\text { (vă)zut }\end{array}$ & $\begin{array}{l}64 \\
61 \\
\end{array}$ & $\begin{array}{l}\mathbf{8 1} \\
70 \\
\end{array}$ & $\begin{array}{l}277 \\
168 \\
\end{array}$ & $\begin{array}{l}264 \\
160 \\
\end{array}$ & $\begin{array}{l}233 \\
177 \\
\end{array}$ & "nu zút & $\begin{array}{l}\text { nu: I, F0 } \\
\text { zut: I }\end{array}$ \\
\hline & $\begin{array}{l}\text { 14_1 n-am } \\
\text { (vă)zut }\end{array}$ & $\begin{array}{l}143 \\
103\end{array}$ & $\begin{array}{l}72 \\
74\end{array}$ & $\begin{array}{l}177 \\
\mathbf{2 1 0}\end{array}$ & $\begin{array}{l}193 \\
212\end{array}$ & $\begin{array}{l}212 \\
211\end{array}$ & "n-am zút & $\begin{array}{l}\text { n-am: } \mathrm{D}, \mathrm{F} 0 \\
\text { nivel } \\
\text { maxim pe } \\
m \text {; ve: } \mathrm{I}, \mathrm{F} 0\end{array}$ \\
\hline & $\begin{array}{l}\text { 14_2 n-am } \\
\text { (vă)zut }\end{array}$ & $\begin{array}{l}\mathbf{1 2 5} \\
74\end{array}$ & $\begin{array}{l}77 \\
75\end{array}$ & $\begin{array}{l}225 \\
221\end{array}$ & $\begin{array}{l}\mathbf{2 5 6} \\
227\end{array}$ & $\begin{array}{l}255 \\
217\end{array}$ & "n-am zút & $\begin{array}{l}\text { n-am: D; I, } \\
\text { F0 }\end{array}$ \\
\hline & $\begin{array}{l}\text { 14_3 n-am } \\
\text { (vă)zut }\end{array}$ & $\begin{array}{l}112 \\
97\end{array}$ & $\begin{array}{l}79 \\
67 \\
\end{array}$ & $\begin{array}{l}\mathbf{2 1 8} \\
176 \\
\end{array}$ & $\begin{array}{l}\mathbf{2 3 1} \\
168 \\
\end{array}$ & $\begin{array}{l}235 \\
172 \\
\end{array}$ & "n-am zút & n-am: I, F0 \\
\hline \multirow[t]{6}{*}{ Cs6 } & $\begin{array}{ll}\text { twkm1 nu } & \begin{array}{l}\text { ve } \\
\end{array}\end{array}$ & $\begin{array}{l}113 \\
120\end{array}$ & $\begin{array}{l}\mathbf{8 1} \\
80\end{array}$ & $\begin{array}{l}138 \\
117\end{array}$ & $\begin{array}{l}\mathbf{1 5 0} \\
120\end{array}$ & $\begin{array}{l}130 \\
131\end{array}$ & "nu vé & nu: I, F0 \\
\hline & $\begin{array}{ll}\text { twkm2 nu } & \begin{array}{l}\text { ve } \\
\end{array}\end{array}$ & $\begin{array}{l}\mathbf{1 4 7} \\
115\end{array}$ & $\begin{array}{l}78 \\
78\end{array}$ & $\begin{array}{l}123 \\
118\end{array}$ & $\begin{array}{l}142 \\
128\end{array}$ & $\begin{array}{l}139 \\
134\end{array}$ & "nu vé & nu: D, F0(2) \\
\hline & $\begin{array}{ll}\text { twkm3 nu } & \text { ve }\end{array}$ & $\begin{array}{l}124 \\
121\end{array}$ & $\begin{array}{l}82 \\
79\end{array}$ & $\begin{array}{l}140 \\
115\end{array}$ & $\begin{array}{l}\mathbf{1 6 4} \\
119\end{array}$ & $\begin{array}{l}187 \\
132\end{array}$ & "nu vé & nu: I, F0 \\
\hline & $\begin{array}{c}12 \_1 \text { nu } \\
\text { (vă)zut }\end{array}$ & $\begin{array}{l}55 \\
65\end{array}$ & $\begin{array}{l}84 \\
64\end{array}$ & $\begin{array}{l}\mathbf{1 6 3} \\
86\end{array}$ & $\begin{array}{l}\mathbf{1 5 0} \\
88\end{array}$ & $\begin{array}{l}\mathbf{1 3 6} \\
86\end{array}$ & "nu zút & nu: I, F0 \\
\hline & $\begin{array}{l}12 \_ \text {nu } \\
\text { (vă)zut }\end{array}$ & $\begin{array}{l}59 \\
65\end{array}$ & $\begin{array}{l}81 \\
67\end{array}$ & $\begin{array}{l}\mathbf{2 3 0} \\
93\end{array}$ & $\begin{array}{l}\mathbf{2 2 5} \\
92\end{array}$ & $\begin{array}{l}199 \\
91\end{array}$ & "nu zút & nu: I, F0 \\
\hline & $\begin{array}{l}\text { 14_1no-am } \\
\text { (vă)zut }\end{array}$ & $\begin{array}{l}109 \\
62\end{array}$ & $\begin{array}{l}81 \\
68\end{array}$ & $\begin{array}{l}146 \\
95\end{array}$ & $\begin{array}{l}147 \\
93\end{array}$ & $\begin{array}{l}\mathbf{1 3 3} \\
98\end{array}$ & "no-am zút & no-am: D, I, F0 \\
\hline
\end{tabular}




\begin{tabular}{|c|c|c|c|c|c|c|c|c|}
\hline \multirow{14}{*}{ Iș5 } & $\begin{array}{c}\text { twkm1 nu } \\
\text { ve }\end{array}$ & $\begin{array}{l}72 \\
97\end{array}$ & $\begin{array}{l}74 \\
75\end{array}$ & $\begin{array}{l}255 \\
244\end{array}$ & $\begin{array}{l}\mathbf{2 5 5} \\
239\end{array}$ & $\begin{array}{l}243 \\
244\end{array}$ & nù vé & $\begin{array}{l}\text { nu: F0(2) } \\
\text { ve: I }\end{array}$ \\
\hline & $\begin{array}{ll}\text { twkm2 nu } & \text { ve }\end{array}$ & $\begin{array}{l}78 \\
88\end{array}$ & $\begin{array}{l}74 \\
75\end{array}$ & $\begin{array}{l}231 \\
230\end{array}$ & $\begin{array}{l}\mathbf{2 3 5} \\
218\end{array}$ & $\begin{array}{l}232 \\
219\end{array}$ & nù vé & nu: F0(2) \\
\hline & twkm3 nu & 91 & 73 & 223 & 227 & 219 & nu vé & ve: I \\
\hline & ve & 92 & 77 & 232 & 220 & 224 & & \\
\hline & $12 \_1 \mathrm{nu}$ & 57 & 70 & 289 & 307 & 304 & "nu zút & nu: I, F0 \\
\hline & (vă)zut & 49 & 67 & 182 & 180 & 175 & & \\
\hline & $1222 \mathrm{nu}$ & 68 & 72 & 237 & 269 & 289 & "nu zút & nu: I, F0 \\
\hline & (vă)zut & 62 & 63 & 181 & 174 & 169 & & \\
\hline & $123 \mathrm{nu}$ & 69 & 71 & 251 & 287 & 299 & "nu zút & nu: D, I, F0 \\
\hline & (vă)zut & 50 & 65 & 172 & 168 & 164 & & \\
\hline & 14_1 n-am & 81 & 73 & 269 & 287 & 306 & "n-am zút & n-am: D, I, F0 \\
\hline & (vă)zut & 48 & 70 & 218 & 217 & 215 & & \\
\hline & 14_2n-am & 95 & 74 & 259 & 278 & 294 & "n-am zút & n-am: D, I, F0 \\
\hline & (vă)zut & 58 & 65 & 194 & 185 & 181 & & \\
\hline \multirow{18}{*}{ Iș6 } & twkm1 nu & 74 & 69 & 118 & 114 & 107 & nu vé & ve: I \\
\hline & ve & 86 & 74 & 111 & 106 & 101 & & \\
\hline & twkm2 nu & 62 & 71 & 120 & 120 & 115 & nu vé & ve: I \\
\hline & ve & 93 & 76 & 112 & 110 & 103 & & \\
\hline & twkm3 nu & 91 & 73 & 127 & 124 & 115 & nu vé & ve: I \\
\hline & ve & 88 & 77 & 116 & 113 & 109 & & \\
\hline & 12_1 nu & 53 & 76 & 172 & 171 & 167 & "nu zút & nu: I, F0 \\
\hline & (vă)zut & 104 & 74 & 112 & 108 & 106 & & ve: D \\
\hline & $122 \mathrm{nu}$ & 91 & 81 & 156 & 152 & 144 & "nu zút & ve: I, F0 \\
\hline & (vă)zut & 99 & 74 & 105 & 101 & 104 & & \\
\hline & 12_3 nu & 94 & 74 & 125 & 124 & 123 & "nu zút & nu: I \\
\hline & (vă)zut & 80 & 71 & 113 & 114 & 112 & & \\
\hline & 14_1 n-am & 92 & 79 & 145 & 154 & 157 & "n-am zút & n-am: I, F0 \\
\hline & (vă)zut & 77 & 71 & 115 & 106 & 113 & & \\
\hline & 14_2n-am & 133 & 79 & 161 & 161 & 149 & "n-am zút & n-am: D, I, F0 \\
\hline & (vă)zut & 77 & 72 & 114 & 109 & 103 & & \\
\hline & 14_3 n-am & 132 & 81 & 186 & 171 & 146 & "n-am zút & n-am: D, I, F0 \\
\hline & (vă)zut & 77 & 72 & 107 & 100 & 108 & & \\
\hline \multirow[t]{6}{*}{ T5 } & twkm1 nu & 54 & 71 & 189 & 189 & 190 & nu "ve & ve: I, F0 \\
\hline & & 77 & 80 & 208 & 218 & 221 & & \\
\hline & twkm2 nu & 49 & 68 & 180 & 178 & 177 & nu "ve & ve: I, F0 \\
\hline & ve & 64 & 75 & 197 & 204 & 206 & & \\
\hline & twkm3 nu & 61 & 73 & 176 & 173 & 174 & nu "ve & ve: I, F0 \\
\hline & ve & 73 & 80 & 190 & 200 & 203 & & \\
\hline
\end{tabular}




\begin{tabular}{|c|c|c|c|c|c|c|c|c|}
\hline & $\begin{array}{c}12 \_1 \text { nu } \\
\text { (vă)zut }\end{array}$ & $\begin{array}{l}66 \\
45\end{array}$ & $\begin{array}{l}71 \\
68\end{array}$ & $\begin{array}{l}\mathbf{2 3 3} \\
197\end{array}$ & $\begin{array}{l}239 \\
201\end{array}$ & $\begin{array}{l}239 \\
195 \\
\end{array}$ & 'nu/"nu zút & nu: D, I, F0 \\
\hline & $\begin{array}{l}12 \_ \text {nu } \\
\text { (vă)zut }\end{array}$ & $\begin{array}{l}67 \\
71\end{array}$ & $\begin{array}{l}76 \\
74\end{array}$ & $\begin{array}{l}\mathbf{2 4 6} \\
211\end{array}$ & $\begin{array}{l}255 \\
218\end{array}$ & $\begin{array}{l}260 \\
215\end{array}$ & "nu zút & nu: I, F0 \\
\hline & $\begin{array}{c}12 \_3 \text { nu } \\
\text { (vă)zut }\end{array}$ & $\begin{array}{l}53 \\
64\end{array}$ & $\begin{array}{l}78 \\
79\end{array}$ & $\begin{array}{l}\mathbf{2 3 6} \\
207\end{array}$ & $\begin{array}{l}239 \\
216\end{array}$ & $\begin{array}{l}242 \\
219\end{array}$ & 'nu zút & $\begin{array}{l}\text { nu: F0 } \\
\text { zut: I }\end{array}$ \\
\hline & $\begin{array}{l}\text { 14_1 n-am } \\
\text { (vă)zut }\end{array}$ & $\begin{array}{l}89 \\
65\end{array}$ & $\begin{array}{l}75 \\
71\end{array}$ & $\begin{array}{l}278 \\
162\end{array}$ & $\begin{array}{l}271 \\
160\end{array}$ & $\begin{array}{l}\mathbf{2 4 4} \\
157\end{array}$ & "n-am zút & $\begin{array}{l}\text { n-am: D, I, } \\
\text { F0 }\end{array}$ \\
\hline & $\begin{array}{l}\text { 14_2 n-am } \\
\text { (vă)zut }\end{array}$ & $\begin{array}{l}99 \\
75\end{array}$ & $\begin{array}{l}82 \\
76\end{array}$ & $\begin{array}{l}264 \\
169\end{array}$ & $\begin{array}{l}269 \\
171\end{array}$ & $\begin{array}{l}261 \\
166\end{array}$ & "n-am zút & $\begin{array}{l}\text { n-am: D, I, } \\
\text { F0 }\end{array}$ \\
\hline & $\begin{array}{l}\text { 14_3 n-am } \\
\text { (vă)zut }\end{array}$ & $\begin{array}{l}84 \\
82\end{array}$ & $\begin{array}{l}80 \\
80\end{array}$ & $\begin{array}{l}228 \\
237\end{array}$ & $\begin{array}{l}237 \\
236\end{array}$ & $\begin{array}{l}\mathbf{2 4 8} \\
222\end{array}$ & "n-am zút & $\begin{array}{l}\text { n-am:F0(3), } \\
\text { ni-vel } \\
\text { maxim pe } m\end{array}$ \\
\hline \multirow[t]{9}{*}{ T6 } & $\begin{array}{ll}\text { twkm1 nu } & \text { ve } \\
& \end{array}$ & $\begin{array}{l}73 \\
85\end{array}$ & $\begin{array}{l}68 \\
78\end{array}$ & $\begin{array}{l}93 \\
102\end{array}$ & $\begin{array}{l}93 \\
102\end{array}$ & $\begin{array}{c}90 \\
100\end{array}$ & nu "ve & ve: I \\
\hline & $\begin{array}{ll}\text { twkm2 } & \text { nu } \\
\text { ve }\end{array}$ & $\begin{array}{l}66 \\
73\end{array}$ & $\begin{array}{l}71 \\
77\end{array}$ & $\begin{array}{l}95 \\
107\end{array}$ & $\begin{array}{l}93 \\
107\end{array}$ & $\begin{array}{l}92 \\
107\end{array}$ & nu "ve & ve: I, F0 (3) \\
\hline & $\begin{array}{ll}\text { twkm3 nu } & \text { ve }\end{array}$ & $\begin{array}{l}75 \\
86\end{array}$ & $\begin{array}{l}71 \\
81\end{array}$ & $\begin{array}{l}94 \\
105\end{array}$ & $\begin{array}{l}94 \\
106\end{array}$ & $\begin{array}{l}94 \\
107\end{array}$ & nu "ve & ve: I \\
\hline & $\begin{array}{c}12 \_1 \text { nu } \\
\text { (vă)zut }\end{array}$ & $\begin{array}{l}67 \\
50\end{array}$ & $\begin{array}{l}73 \\
68\end{array}$ & $\begin{array}{l}\mathbf{1 7 0} \\
107\end{array}$ & $\begin{array}{l}185 \\
108\end{array}$ & $\begin{array}{l}195 \\
93\end{array}$ & "nu zút & nu: D, I, F0 \\
\hline & $\begin{array}{l}12 \_\mathrm{nu} \\
\text { (vă)zut }\end{array}$ & $\begin{array}{l}68 \\
77\end{array}$ & $\begin{array}{l}79 \\
77\end{array}$ & $\begin{array}{l}149 \\
111\end{array}$ & $\begin{array}{l}162 \\
108\end{array}$ & $\begin{array}{l}\mathbf{1 6 8} \\
97\end{array}$ & "nu zút & nu: I, F0 \\
\hline & $\begin{array}{c}12 \_3 \text { nu } \\
\text { (vă)zut }\end{array}$ & $\begin{array}{l}60 \\
56 \\
\end{array}$ & $\begin{array}{l}76 \\
69 \\
\end{array}$ & $\begin{array}{l}\mathbf{1 5 3} \\
107 \\
\end{array}$ & $\begin{array}{l}163 \\
104 \\
\end{array}$ & $\begin{array}{l}170 \\
92 \\
\end{array}$ & "nu zút & nu: I, F0 \\
\hline & $\begin{array}{l}\text { 14_1 n-am } \\
\text { (vă)zut }\end{array}$ & $\begin{array}{l}91 \\
58 \\
\end{array}$ & $\begin{array}{l}83 \\
76 \\
\end{array}$ & $\begin{array}{l}\mathbf{1 7 1} \\
115 \\
\end{array}$ & $\begin{array}{l}\mathbf{1 8 4} \\
114 \\
\end{array}$ & $\begin{array}{l}\mathbf{1 8 1} \\
106 \\
\end{array}$ & "n-am zút & $\begin{array}{l}\text { n-am: D, I, } \\
\text { F0 }\end{array}$ \\
\hline & $\begin{array}{l}\text { 14_2 n-am } \\
\text { (vă)zut }\end{array}$ & $\begin{array}{l}79 \\
50\end{array}$ & $\begin{array}{l}83 \\
77\end{array}$ & $\begin{array}{l}147 \\
111\end{array}$ & $\begin{array}{l}152 \\
109\end{array}$ & $\begin{array}{l}\mathbf{1 5 0} \\
106\end{array}$ & "n-am zút & $\begin{array}{l}\text { n-am: D, I, } \\
\text { F0 }\end{array}$ \\
\hline & $\begin{array}{l}\text { 14_3 n-am } \\
\text { (vă)zut }\end{array}$ & $\begin{array}{l}87 \\
70 \\
\end{array}$ & $\begin{array}{l}81 \\
75 \\
\end{array}$ & $\begin{array}{l}\mathbf{1 7 5} \\
114 \\
\end{array}$ & $\begin{array}{l}\mathbf{1 9 0} \\
111\end{array}$ & $\begin{array}{l}\mathbf{1 8 5} \\
102 \\
\end{array}$ & "n-am zút & n-am: I, F0 \\
\hline
\end{tabular}

\section{REFERINTTE BIBLIOGRAFICE}

Puşcariu 1976

Puşcariu 1994

Turculeț et alii 2008
= Sextil Puşcariu, Limba română. Vol. I. Privire generală, Prefată de Gavril Istrate, Note, bibliografie de Ilie Dan, Bucureşti, Editura Minerva.

= Sextil Puşcariu, Limba română. Vol II. Rostirea, Ediție îngrijită de Magdalena Vulpe. Studiu introductiv de Andrei Avram, Bucureşti, Editura Academiei Române.

= Adrian Turculeț, Luminița Botoşineanu, Ana-Maria Minut, Constantin-Ioan Mladin, Aspects de la variation diatopique de l'intonation au niveau de la langue roumaine standard, în Adrian Turculeț (ed.), La variation diatopique de l'intonation dans le domaine roumain et roman, Iaşi, EUI, p. 21-72. 
Turculeț, Bleorțu, Bibiri 2015 = Adrian Turculeț, Cristina Bleorțu y Anca Bibiri, Las interrogatives parciales: el contorno melódico típico y desviaciones de naturaleza pragmática, in „Estudios de Fonética Experimental”, XXIV, p. 237-255.

Turculeț 2017

= Adrian Turculeț, Contribuții prozodice la descrierea și delimitarea varietăților regionale ale românei literare vorbite, în „Anuar de lingvistică şi istorie literară", LVII, Bucureşti, p. 365-378.

Turculeț 2018

= Adrian Turculeț, Emfaza lui nu la formele negative ale verbului, în „Fonetică și dialectologie”, XXXVII, p.141-160.

\section{THE EMPHASIS OF NU IN THE NEGATIVE FORMS OF THE VERB}

\section{ABSTRACT}

The emphasis of the adverb $n u$ in the negative forms of the verb is considered a specific trait of Romanian language. This paper (first part in FD XXXVII), based on a corpus extracted from the AMPROM

Archive, investigates the auditory prominence of $n u$ in relation to the accented vowel of the verb, using the main acoustic properties (duration, intensity and fundamental frequency) of the vowels $(n) u$ and $(v) e(d e),(v \breve{a z}) u(t)$. The adverb $n u$ is researched in the following contexts: 1 . Inside of a negative assertive statement: Nevasta nu vede un căpitan (1st part). 2. Inside of a negative interrogative sentence: Nevasta nu vede un căpitan? 3. At the beginning of a negative assertive sentence: $N u$ l-am văzut pe Ion/Mihai. 4. In the third position, and followed by the vowel $a$, in which case $n u$ takes the allomorfs $n u$-, $n$-: $N u$-am/N-am văzut fetele.

The frequency of the emphatical pronounciation of $n u$ in our corpus was about $50 \%$ in the first position, about $80-90 \%$ in the third or fourth position, and it rarely appeared (about $9 \%$ ) in the second position. Therefore, we suggest that the appearance of the emphatical pronounciation of $n u$ (followed by its quasi-generalization), took place initially in the third/fourth positions, and then was expanded to the first position. In contrast, the extension of the emphasis to the second position remained secondary.

Universitatea „Alexandru Ioan Cuza” din Iaşi Bulevardul Carol I nr. 11 